\title{
الشعور بالنقص وعلاقته بمعنى الحياة لدى طلبة الجامعة
}

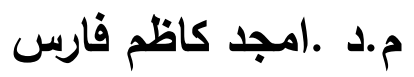 \\ كلية الإمام الكاظم الجامعة للعلوم الاسلامية
}

الماخص:

الشعور بالنقص هو شعور ينتاب الفرد في حياته ويرتبط هذا الثعور بشكل كبير بتقدير ذات منخفض من

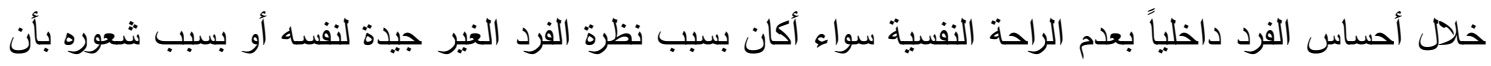

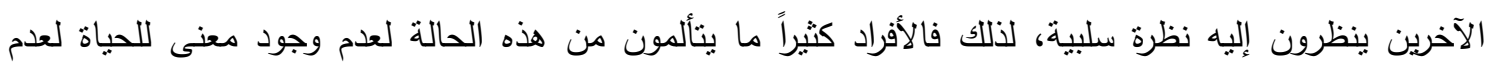

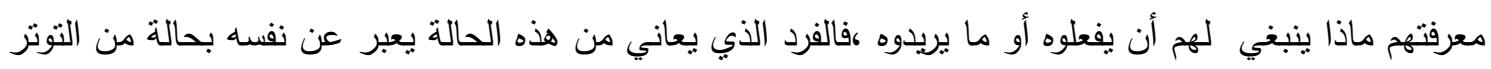

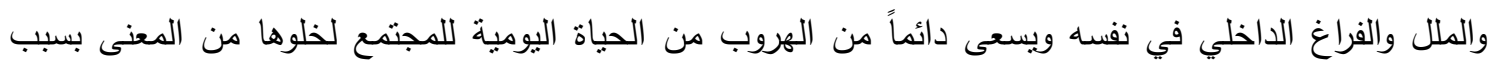
أنتطته التي ليس لها معنى ،و استهدف البحث الحالي التعرف على الثعور بالنقص لدى طلى للبة الجامعة كذللك، معنى الحياة وطبيعة العلاقة بين الثعور بالنقص ومعنى الحياة لدى طلبة الجامعة ،وتتطلب ذلك بناء إداتان لقياس

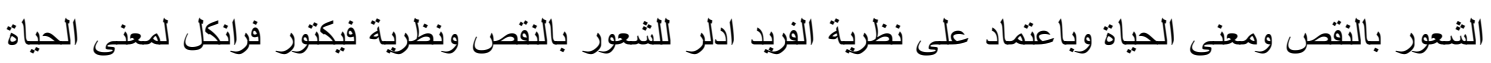
وطبق المقياسان على عينة البحث وهم طلبة الجامعة، وكانت النتائج وجود شعوراً بالنقص ومعنى للقئ للحياة ، وتوجند

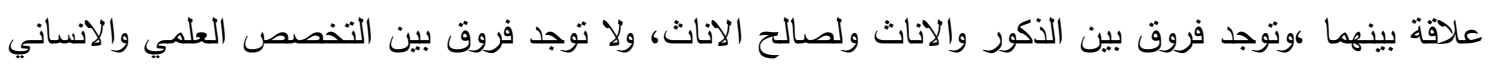
بالنسبة لمتغير الثعور بالنقص، وكذلك توجد فروق بين الذكور والاناث ولصالح الذكور، والتخصص التصن العلمي والانساني ولصالح التخصص العلمي لمتغير معنى الحياة، وخرج البحث بعدد من التوصيات والمقترحات.

\section{مشكلة البحث:}

الثعور بالنقص هو شعور ينتاب الفرد في حياته ويرتبط هذا الثُعور بشكل كبير بتقدير ذات منخفض من خـلال أحساس الفرد داخلياً بعدم الراحة النفسية سواءاً أكان بسبب نظرة الفرد الغير جيدة لنفسه أو بسبب شعوره بان الآخرين ينظرون إليه نظرة سلبية، والسبب الرئيس لهذا الثعور عند الفرد هو الخبرات التعليمية السابقة، والتي عادة ما تكون في مرحلة الطفولة والمراحل الأخرى الته من حياة الفرد، لان الاباء غالباً ما يكون لديهم مقاييس صارمة وعالية يحاولون أن يتابعوا أولادهم عما يفعلوه دائمسا فبدل ان يشجعوهم ويقدموا لهم الدعم، يقوم الكثير منهم في كثير من الأحيان بلومهم وانتقادهم ومعاقبتهم، لذلك يتولد لديهم احساس بالثعور بالنقص، ولذلك يشير ادلر إلى أن

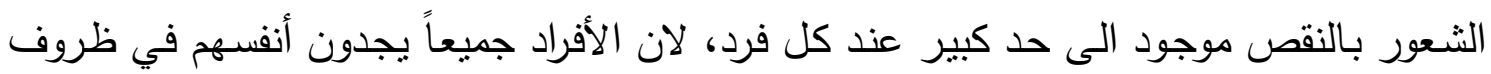
وأحوال يرغبون في تحسينها، لذلك فان الشعور بالنقص سواءً أكان حقيقياً أو وهمياً فالفرد يحاول باستمرار مواجهة مواقف الحيـاة المختلفة لكي يسـ النقص الذي يثـعر بـه وقد يفشـل الفرد في التعويض، لذا يحاول أن يضـع لنفسه أهداف خيالية من اجل أن يظهر تفوقه الثخصي، السيطرة على الآخرين، وهو بذلك غير دقيق في تقدير ذاته،ودائماً ما ينتابه التوتر ويخشى اتخاذ القرارات ويعاني من فقدان المعنى في حياته(Adler,1931,p:52 ). 
يشير فرانكل أن ما يتعرض له الفرد من حالات نوتر وإحباط واضطرابات في حياته، وذللك

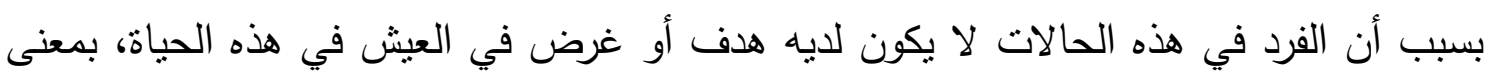

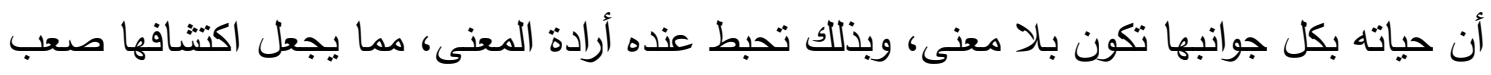

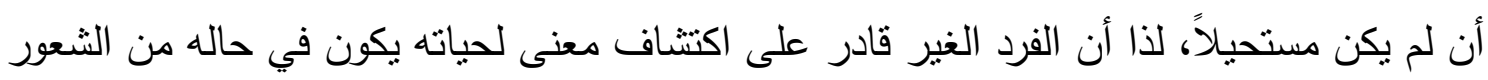

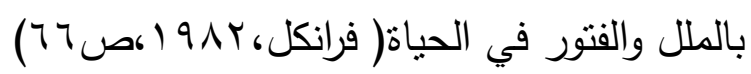
فالأفراد كثيراً ما يتألمون من عدم وجود معنى للحياة لعدم معرفتهم ماذا ينبغي لهم أن أن يفعلوه

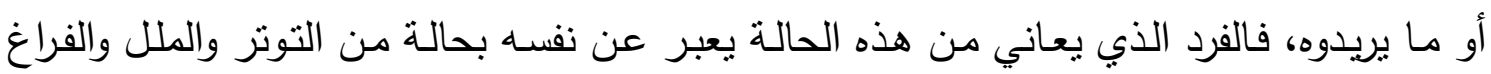

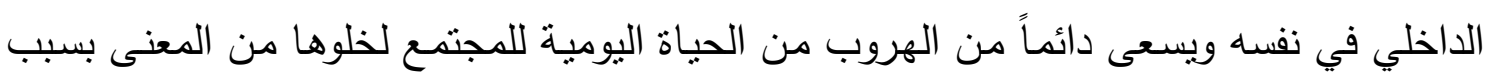

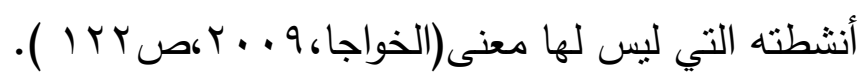

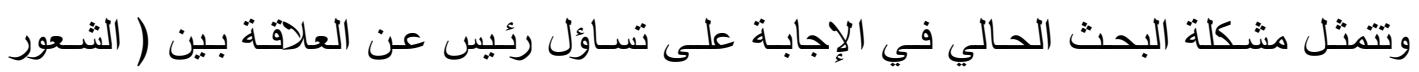
بالنقص ومعنى الحياة لدى طلبة الجامعة)

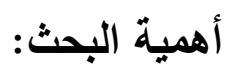

الثعور بالنقص من المتغيرات التي صاغها ادلر ولقيت قبولاً لاى علماء النفس بل لدى عامة

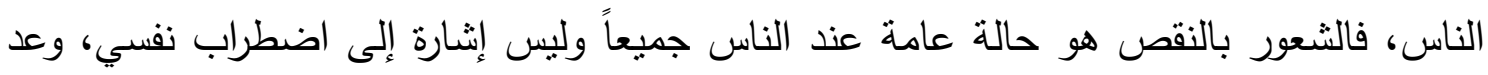

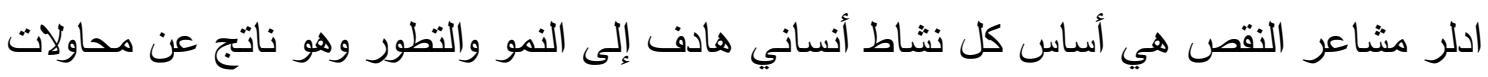

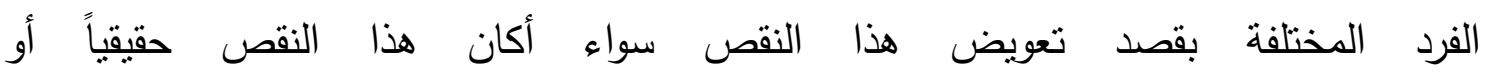

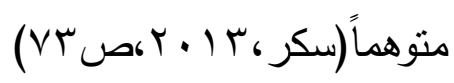

يرى ادلر أن الثعور بالنقص هو أمر طبيعي يحدث لجميع الإقراد، بل انه يعتبر السبب في

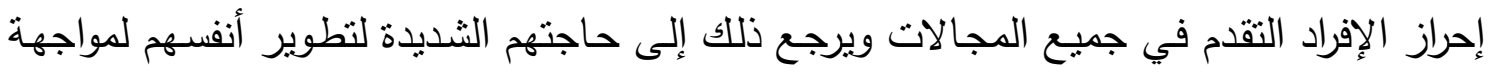

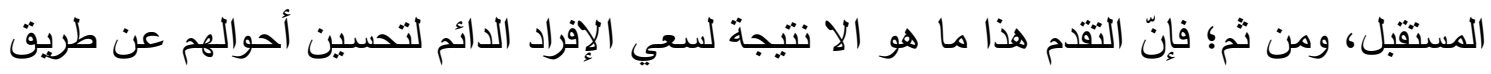

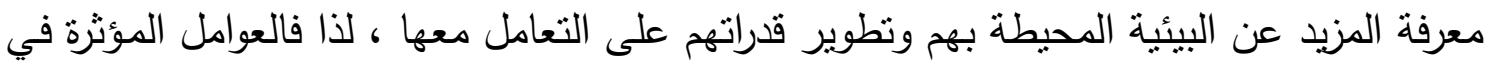

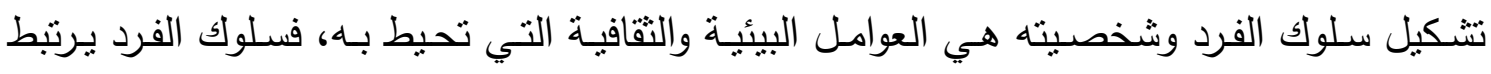

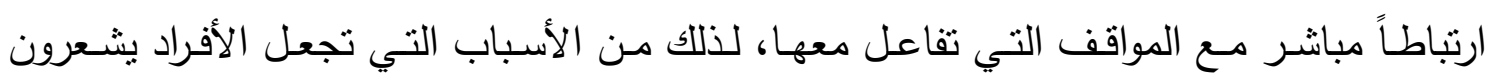

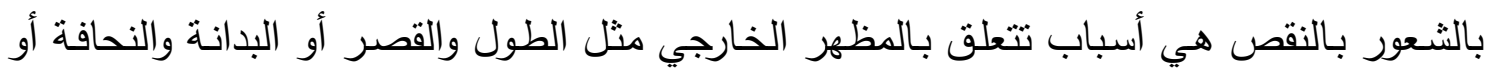

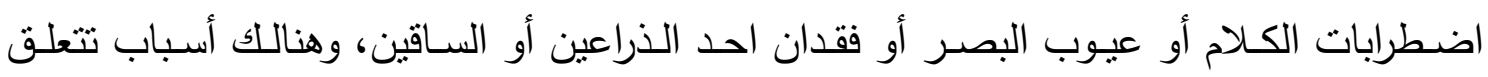

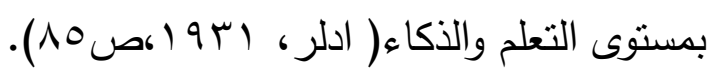

إن الثعور بالنقص يكون حالة صحية وناجحة ومثمرة عندما يؤدي إلى انجازات مهمة

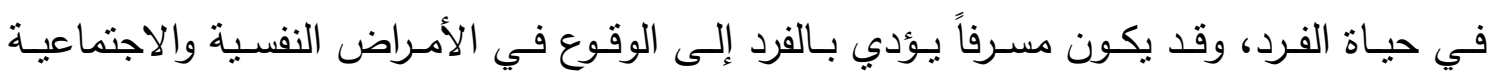




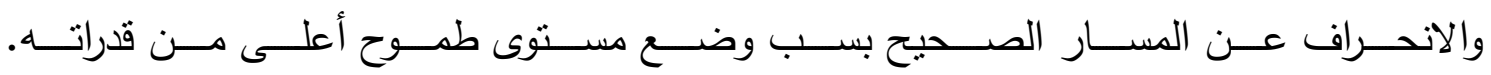

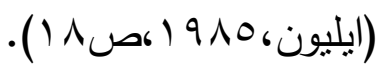

وقد أكدت ذلك دراسة كل من شيلت و ويتتك 1995 Child and Whiting إذ بينت أن

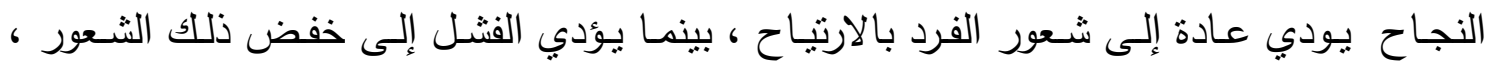

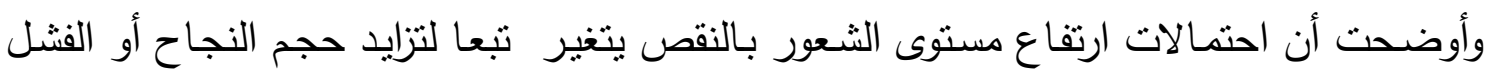
• (Child and Whiting, 1995 ,P303 ) أما Guilford1999؛ فقد أثنار أن الفثل والنجاح مسالة نسبية ، فمــا يعـده شخص

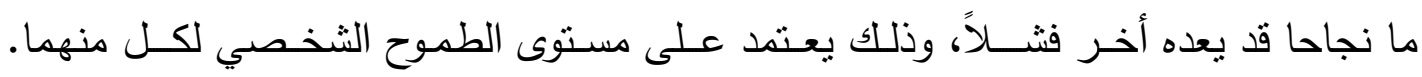
(Guilford ,1999,p.314)

يشير ادلر أن الفرد المصـاب بعجز أو قصور في عضو مـا يحاول دائمـاً تعويض هذا التقص من خلال (النضال أو الكفاح ) والذي يعد بمثابة ضرورة واقعية لطرح كل الحلول المناحة

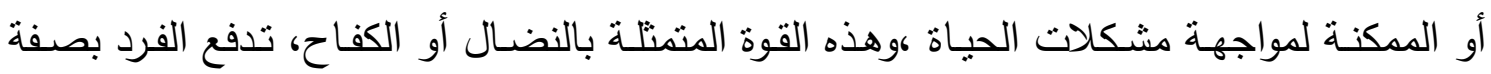

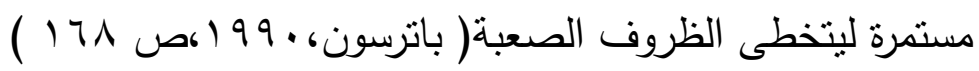

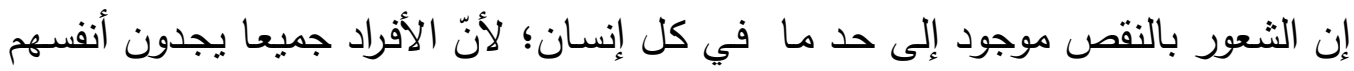

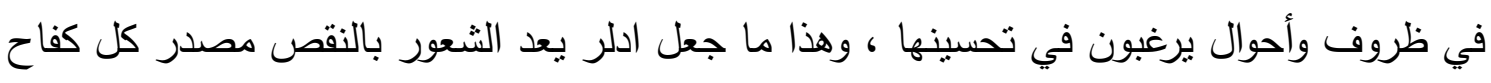
الإنسان ، إذ أن كل تقدم وتطور ينتج من محاولة تعويض ناجحة عن النقص سواء أكان هذا

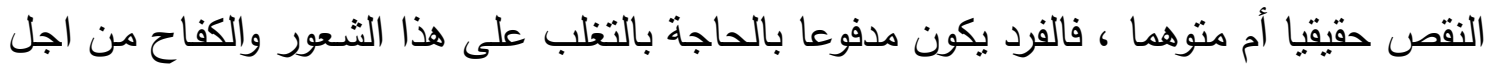

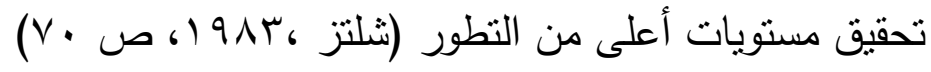
ويعد معنى الحياة من الموضوعات التي تؤكد ايجابية الثخصية الإنسانية، كذلك تمنل نواة

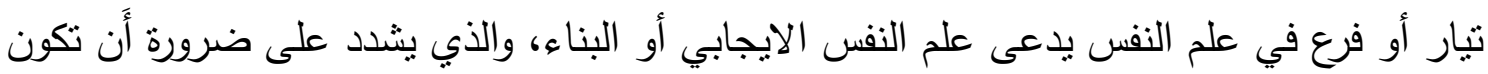

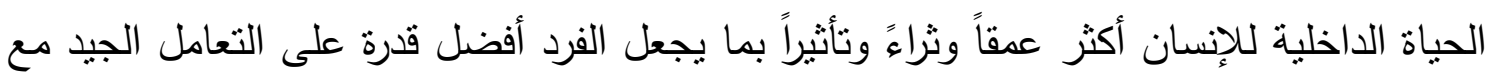
أقسى الظروف المحيطة به ، وينسجم هذا التوجه مع دعوة سليجمان ( Seligman ) الذي يؤكد

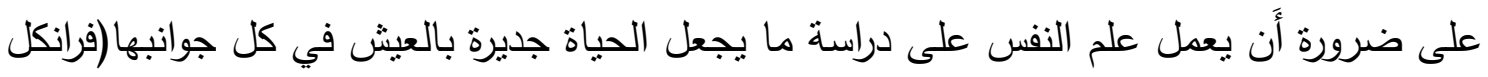
( $\leqslant 7$ (9) 910، ويندرج مفهوم معنى الحياة ضمن التوجه الإيجابي في علم النفس والذي يرجع في أصوله إلى في الذي

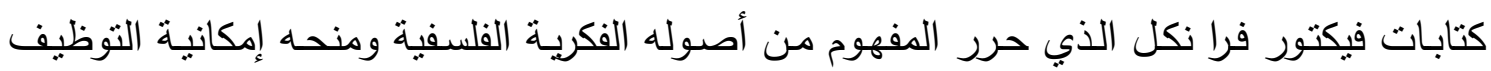

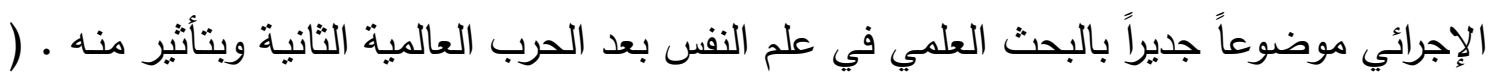

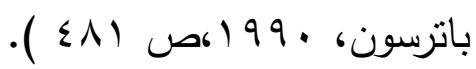


ويؤكد فرانكل أهمية انه يجب حث الأفراد على أَن يجدوا هدفاً ومقصداً لوجودهم من أجل

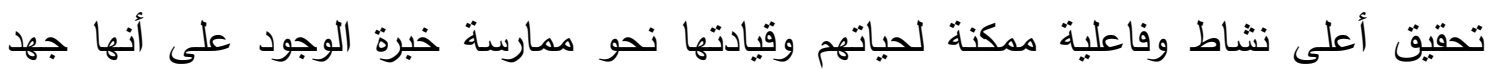

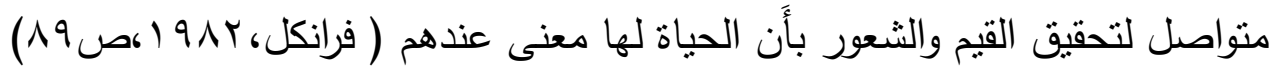

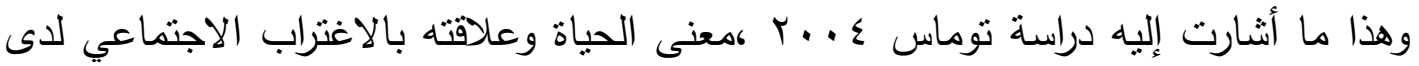

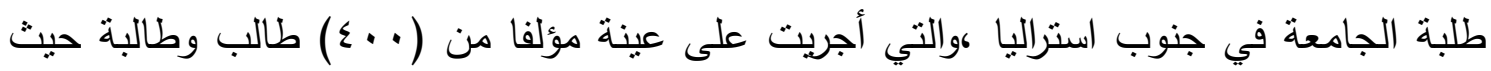
كثفت الدراسة الى أن أفراد العينة لديهم معنى للحياة. (Thimos, 2004, P.95).

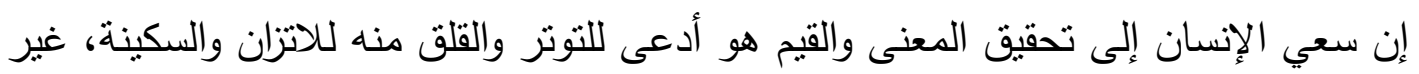

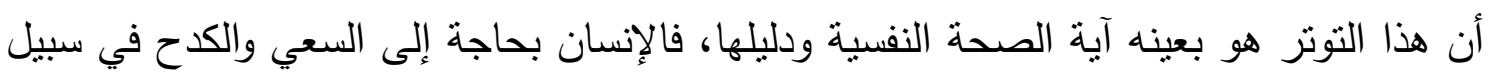

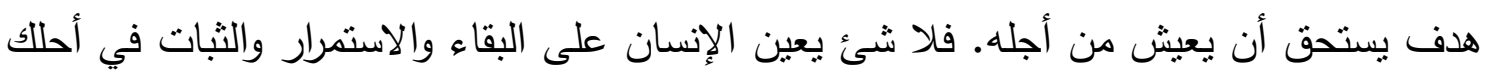

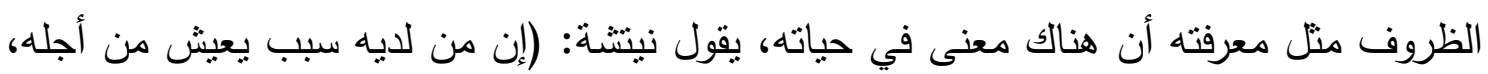

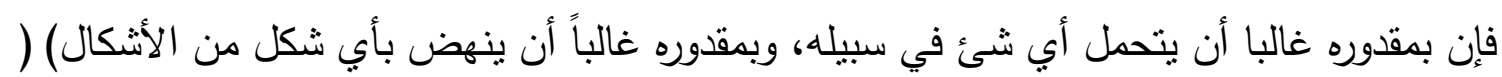

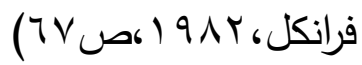

وهذا ما اشارت اليه دراسة كاينر 2009 ,(معنى الحياة وعلاقتها بالضغوط النفسية) أجريت

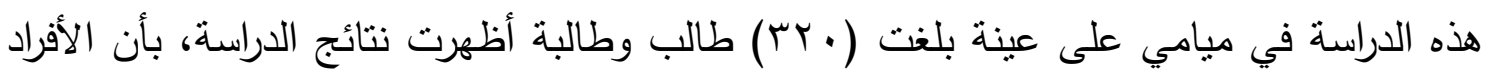

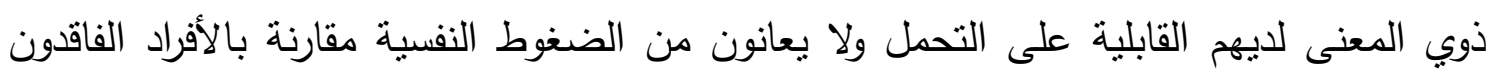

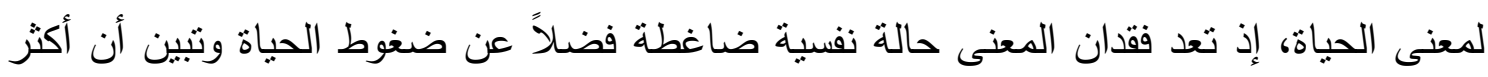

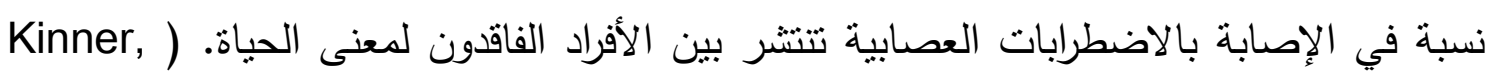
.(2009, P.56

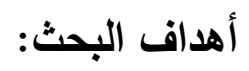

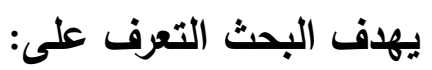
1 إلثعور بالنقص لدى طلبة الجامعة. r بـ معنى الحياة لدى طلبة الجامعة.

rـ دلالة الفروق في مستوى الثعور بالنقص لدى طلبة الجامعة وفقاً لمتغير الجنس(ذكور . إناث ) و التخصص (علمي ـ أنساني) ع ـ دلالة الفروق في مسنوى معنى الحياة لدى طلبة الجامعة وفقاً لمتغير الجنس(ذكور . إناث) والتخصص (علمي ـ أنساني) ○ـ طبيعة العلاقة بين الثعور بالنقص ومعنى الحياة لدى طلبة الجامعة. 
حدود البحث:

يتحدد البحث الحالي على طلبة الجامعة المستصرية للاراسات الصباحية، وفق التخصص

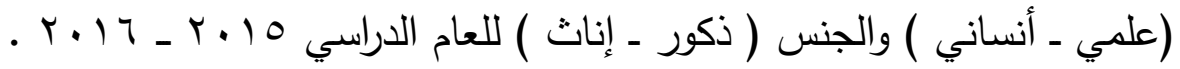

$$
\begin{aligned}
& \text { مصطلحات البحث: }
\end{aligned}
$$

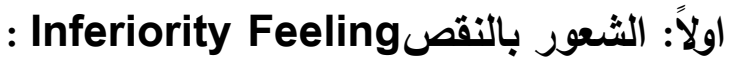

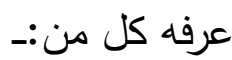

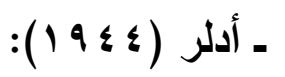

شعور الفرد بالضعة وانه أدنى من الآخرين ، نتيجة قصور عضوي أو معنوي أو اجتماعي

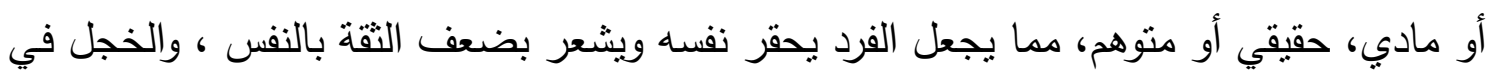
المواقف الاجتماعية ،و ضعف القدرة في اتخاذ القرار، مما يدفحه إلى السعي للتقوق في محاولة للتحرر من الثعور النقص والوصول إلى الكمال من خلال التعويض عن النقص ( أدلر ، ؟ ؟ 1 ا،

$$
\text { - ايليون(1910) }
$$

شعور الفرد أن فيه قصور ما، حقبقي أو منوهم، يقلل ثقته في نفسه، ويسبب لـه اضطراباً

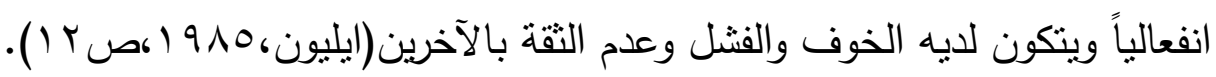

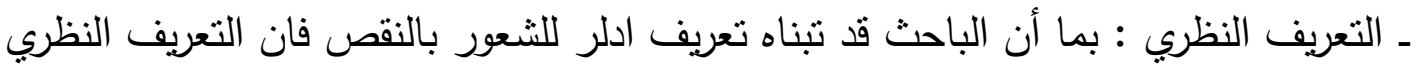
هو نفسه المشار إليه أعلاه. ـ التعريف الإجرائي :هو الدرجة الكلية التي يحصل عليها المجيب على فقرات مقياس الثعور

ثانياً: معنى الحياة meaning of life

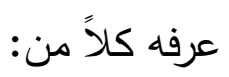

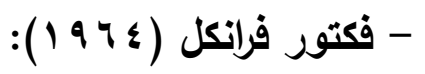
هي قدرة الفرد على أن يكتثف وبشكل مسؤول المعاني الحياتيـة المتأصلة في سلوكه ومواقفه (Frankl , 1964, P.132 )

$$
\text { - رايف (1989): }
$$

ـ هو التأكيد على الاستيعاب الواضح لغرض الحياة والإحساس بالاتجاه والقصدية بوصفها مؤشرات للثعور بان الحياة ذات هدف (Ryff, 1989 P. 1074). 
ـ التعريف النظري : بما أن الباحث قد تبناه تعريف فيكتور فرانكل لمعنى الحياة فان التعريف

$$
\text { النظري هو نفسه المشار إليه أعلاه. }
$$

ـ التعريف الإجرائي :هو الدرجة الكلية التي يحصل عليها المجيب على فقرات مقياس معنى إلى

Inferiority Feeling اولاً: الشعور بالنقص الثطري

$$
\text { نظرية:الفريد ادلر }
$$

إنّ الثعور بالنقص واحدة من أهم اكتثافات علم النفس الفردي، فقد أصبح معروفة في جميع

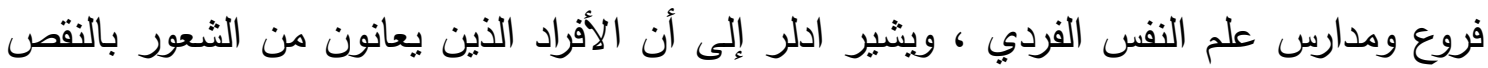
يمكننا التعرف عليهم من خلال المواقف التي يشعرون فيها غير قادرين على الحياة بطريقة مفيدة

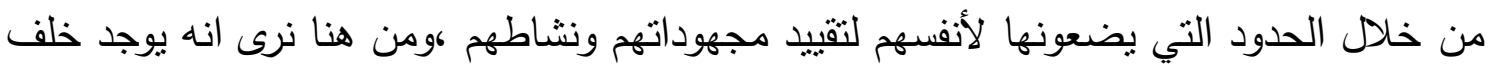

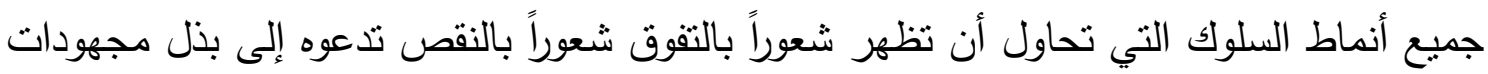

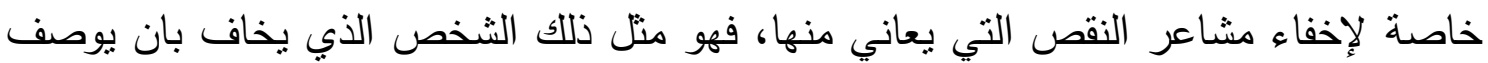
بقصر القامة فيقوم بالمشي على أطراف أصابع قدميه حتى يظهر بأنه أطول من حقيقته، وكذلك الكاءل

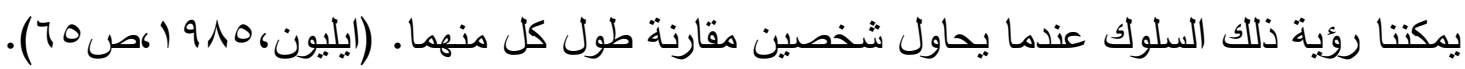
يشير ادلر إلى أن مشاعر الضغوط ينتج عنها الكثير من الضغوط فإنه سيكون هناللك دائما رد فعل في محاولة لتعويض الثعور بالنقص عن طريق النظاهر بالثعور بالتقوق، ولكن رد الفعل هذا لن يكون في اتجاه محاولة حل المشكلة ذاتها، وبهذا تكون الحركة نحو محاولة التظاهر بالتفوق محاولة عديمة الفائدة في الحياة لان الشكلة ستكون مركونة دون محاولة حقيقة للتعامل معها، وبالتالي فان الأفراد سيحاولون تضييق مجال حركتهم محاولة منهم تجنب الهزيمة بدلاً من من لهان

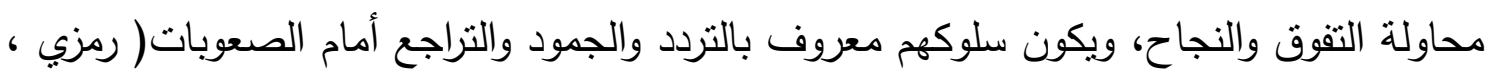

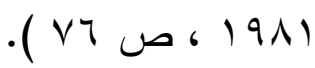
وقد بيّن أدلر أن الفرد الذي يمثلك عضواً قاصراً أو ضعيفاً بعوض ضعفه هذا عن طريق

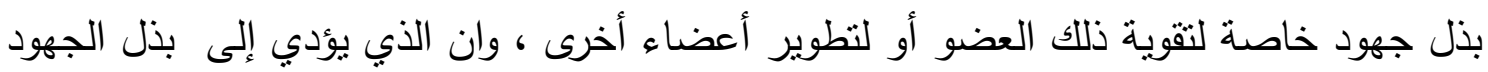
والكفاح ليس هو عجز العضو أو ضعفه بحد ذاته، بل اتجاه الفرد نحو ذلك العجز و الضعف ، وقد استعمل أدلر مصطلح الاتجاه Attitude على انه نزعه أو ميل متعلم بالاستجابة للأشياء والمواقف بثكل ثابت وبطريقة مقبولة أو غبر مقبولة، والمثال النقلبدي الذي قدمه على هذه الحالة هو ديموستين Demosthenes الذي كان بعاني في طفولته من عيوب في النطق ، وعندما بذل جهودا كبيرة للتغلب على هذه العيوب أصبح خطيب اليونان المشهور ، وقد أراد أدلر أن يؤكد وند 
بفكرته الرئيسة هذه أن العضو الجسمي الذي فيه قصورًا أو ضعفاً يؤثر في نمو الثخصية

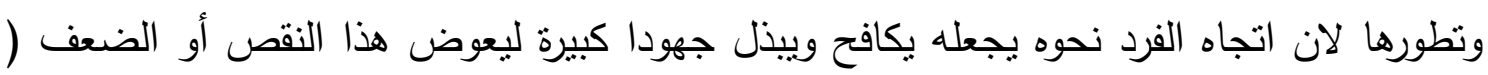

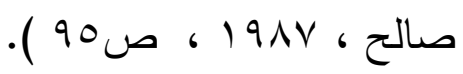
وفي مرحلة لاحقة طوّر أدلر مفهوم الثعور بالنقص العضوي ليشمل مصطلح آخر أبنكره

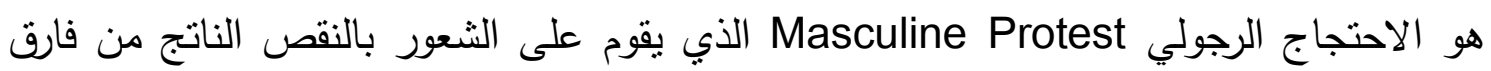
القوة والثجاعة والسلطة بين الجنسين ، إذ ساوى أدلر بين الرجولة والقوة بينما ساوى بين الأنوثة

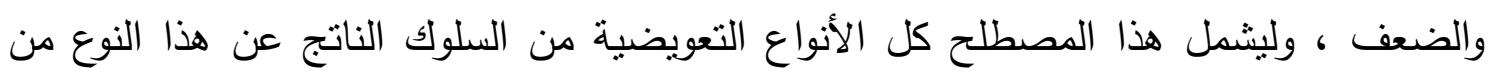

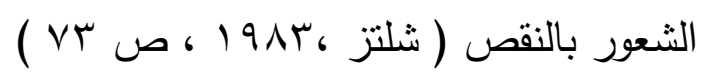
ثم وستع أدلر من مفهوم الثعور بالنقص إذ ذهب إلى أبعد من موضوع النقص العضوي

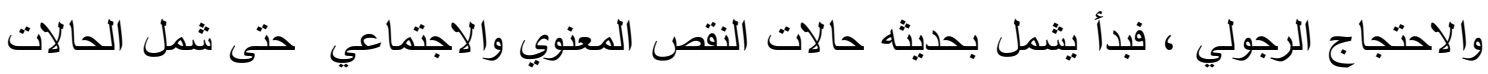

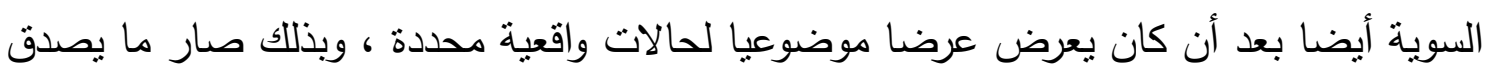

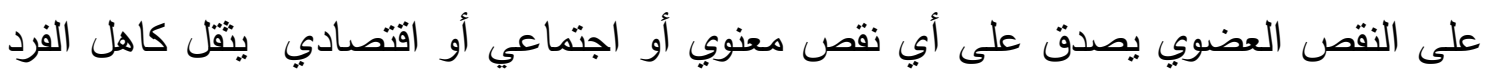

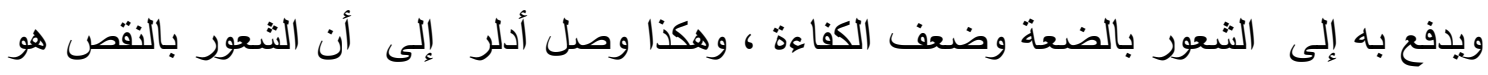

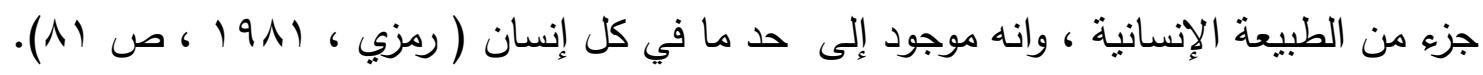

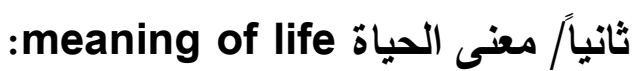
نظرية فكتور فرانكل:

يعدُ فكتور فرانكل المؤسس الأول لما أطلق عليه حديثا علم نفس المعنى ،إذ يقدم تصوراً فريداً

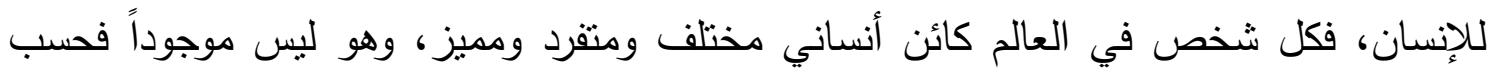

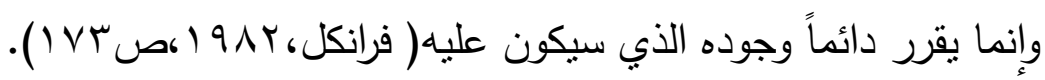

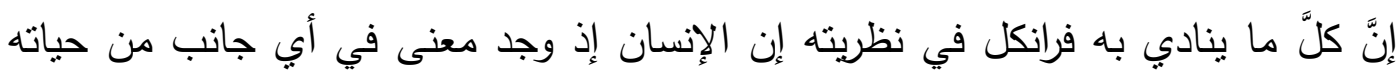

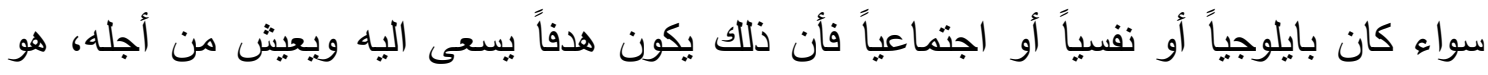

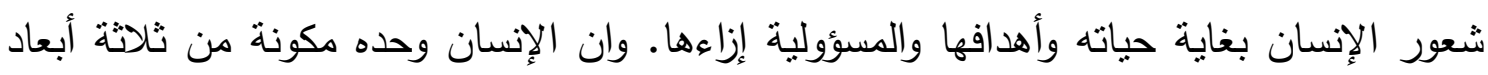

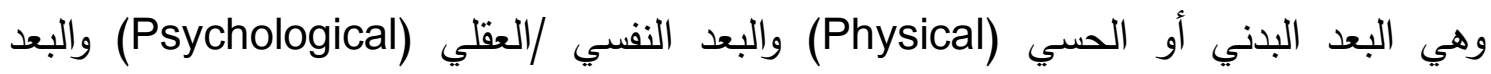
الروحي (Spirituality) الذي يُعد الخاصية الأساسية في نظرية(فرانكل) الوجودية،وان القوة الدافعة

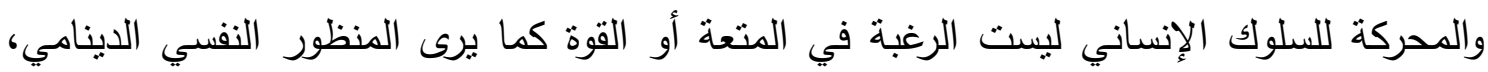

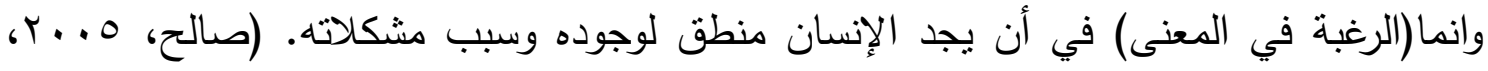

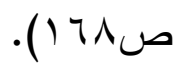
وقد ذكر (فرانكل، ب797 () أن المعنى في الحياة يمكن أن ينبعث من ثلاثة مصادر أساسية 
اـ الانجاز: ويتحقق المعنى في الانجاز من خلال القيام بالنشاطات في المحيط الذي ينتمي اليه كالعمل الذي يزاوله وتلبية حاجاته وحاجات أسرته والإبداع في المجال العنال العلمي. זـ الوجود: ويتحقق المعنى الوجودي من خلال أدراك الفرد لمعنى وجودهُ والتمتع بجمالية

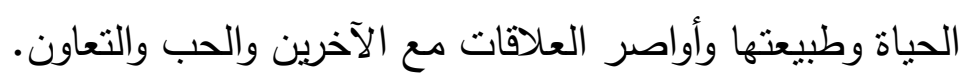
rـ أدراك الفرد: إذ يشتق هذا المعنى من خلال أدراك الفرد للأحداث السلبية والايجابية التي والتي

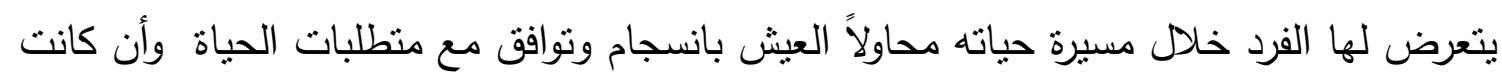
قاسية جعل هناك هدفاً للعيش بدلاً من اليأس والألم. (Thampson,2008,P.23). واقترح فكتور فرانكل انتقال وجهة نظره فيما نتوقع من الحياة الى ماذا الحياة تتوقع منا مؤكداً

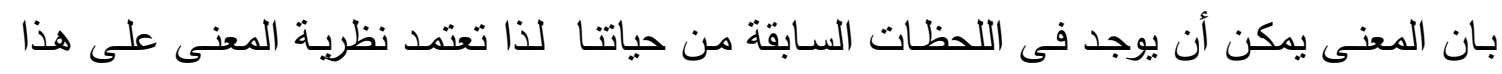
التظظيم الذي يجب استخدامه حتى مع الأفراد الذين يمرون بمواقف خطيرة تهدد حياتهم ويفقدهم

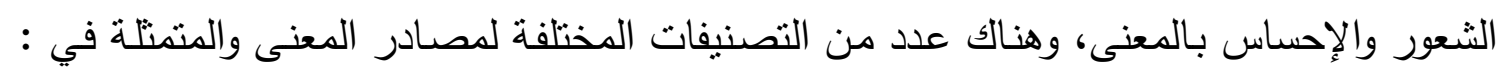

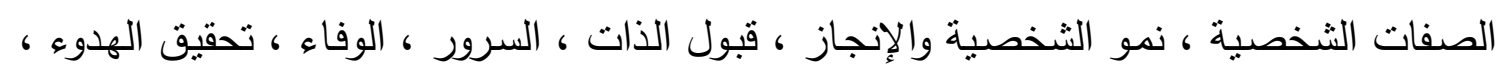

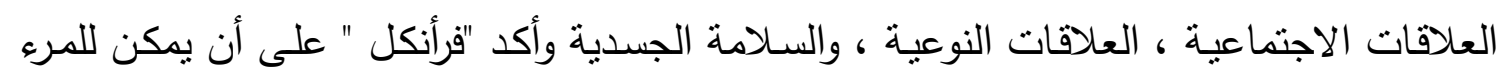

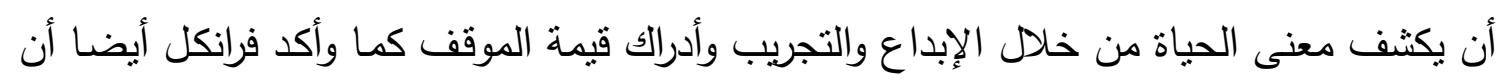

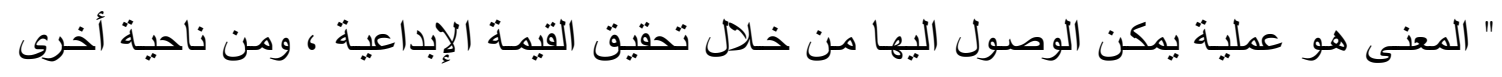

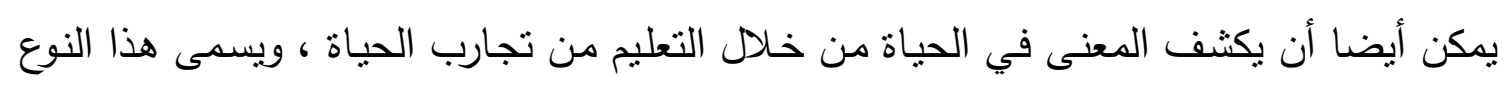

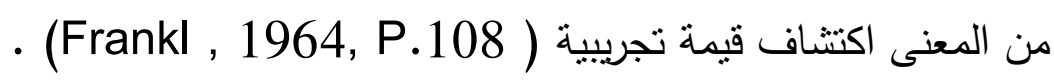
ومما سلف من هذا البحث يتبين مفهوم "معنى الحياة" على انه تفسير لأهمية وجدوى حياة

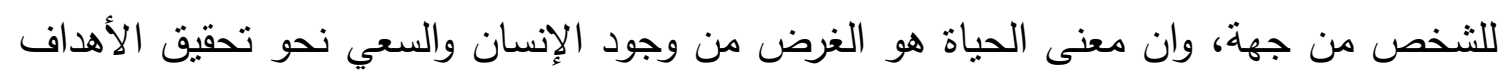

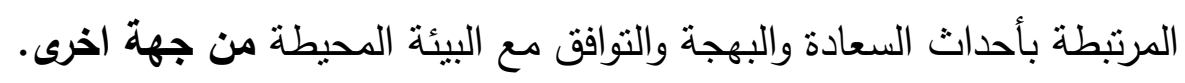

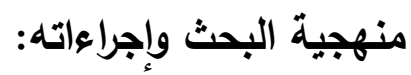
اولاً/ مجتمع البحث: البحث

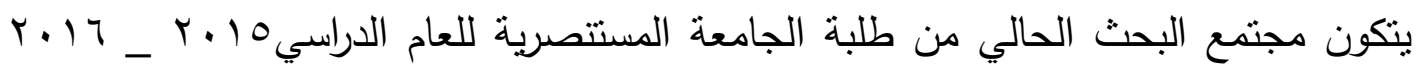

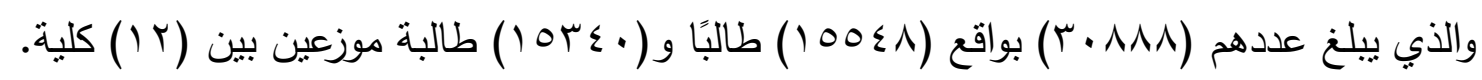

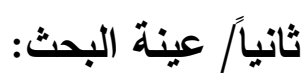

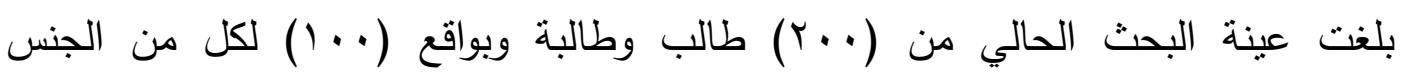
والتخصص ، نم اختبارهم بطريقة عشوائية طبقية والجدول ( ) يوضح ذللك. 


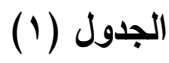

\begin{tabular}{|c|c|c|c|c|}
\hline \multicolumn{5}{|c|}{ توزيع إفراد عينة البحث } \\
\hline المجموع & الإناث & الأكور & الكلية & $ت$ \\
\hline 0 . & ro & ro & الهندسة & 1 \\
\hline 0. & ro & ro & العلوم & $r$ \\
\hline 0. & ro & Yo & التربية & $r$ \\
\hline 0. & Yo & ro & الآداب & $\varepsilon$ \\
\hline$r \ldots$ & $1 \ldots$ & $1 \ldots$ & الحجمو ع & \\
\hline
\end{tabular}

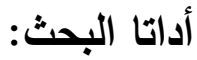
اولاً/ مقياس الثعور بالنقص: التص: تحقيقا لأهداف البحث قام الباحث ببناء مقياس الثعور بالنقص وذللك وفقاً للإطار النظري

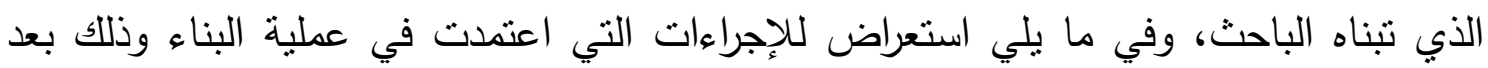

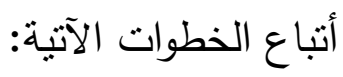
أ. تحديد تعريف مفهوم الثعور بالنقص: قام الباحث بالاطلاع على الإطار النظري للموضوع بغية الإفادة منه في تحديد مفهوم الثعور بالنقص ووفقا لوجهة نظر ادلر فقد تم تعريفه:

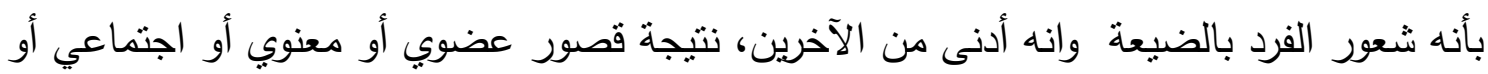

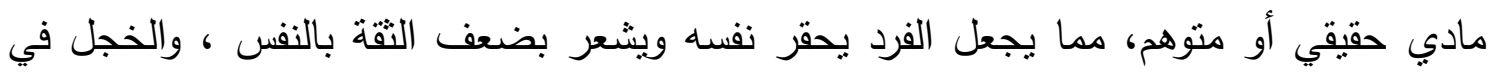

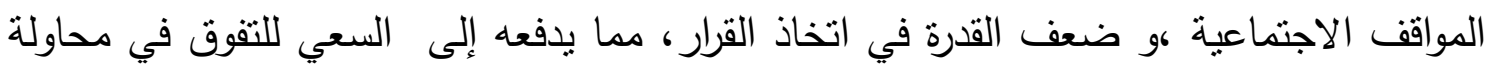

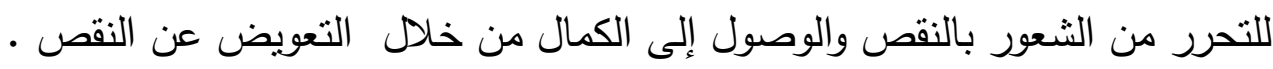
ب . تحديد مجالات الشعور بالنقص: حددت مكونات الثعور بالنقص في ضول الثعاء النظرية والتعريف المتبناة وقد حدد في اربعة مجالات وهي : التبات

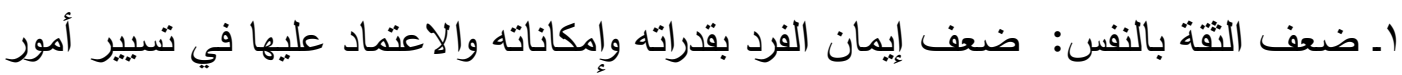

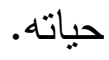
r. الخجل في المواقف الاجتماعية : الميل إلى تجنب التفاعل الاجتماعي ، والفتشل في

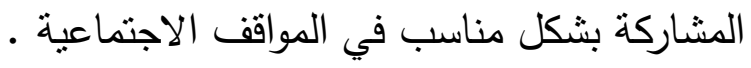

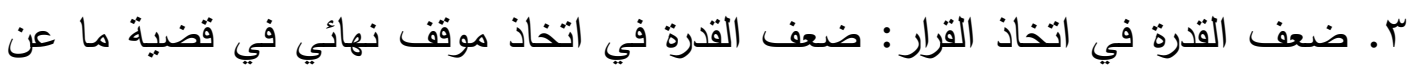

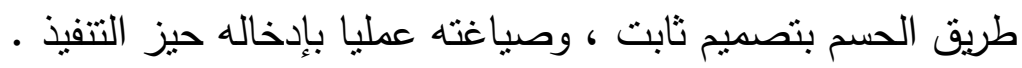

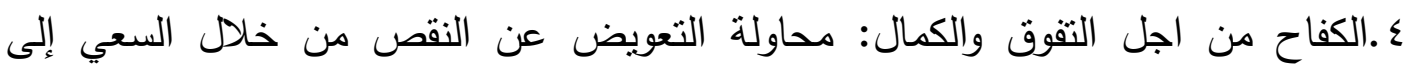

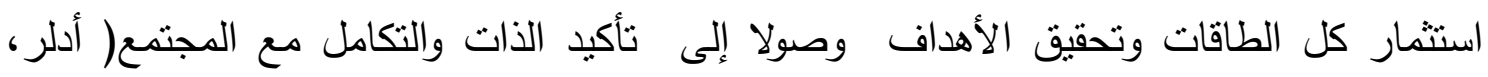
$($ rV

ج ـ صياغة الفقرات: بعد أن تم تحديد تعريف مفهوم الثعور بالنقص فقد نم صياغة الفقرات في ضوء التعريف المشار اليه أعلاه وقد روعي في صياغة أفيد الفقرات أَن تكون مفهومة، وقابلة 
لتفسير واحد ، ولا تجمع بين فكرتين، وذلك بلغت عدد فقرات المقياس بصورته الأولية (ד؟) فقرة والملحق ( ) يوضح ذللك.

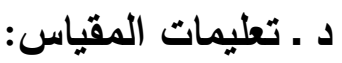

لغرض التعرف على وضوح تعليمات المقياس ووضوح فقراته وبدائله فضلا عن الكثف عن

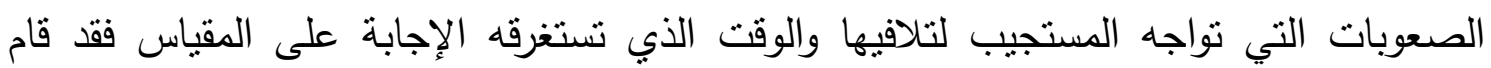

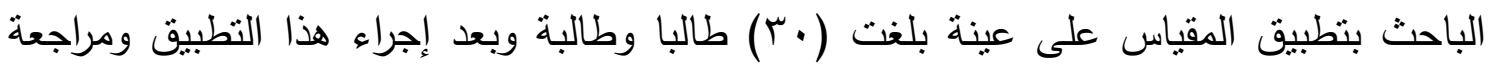

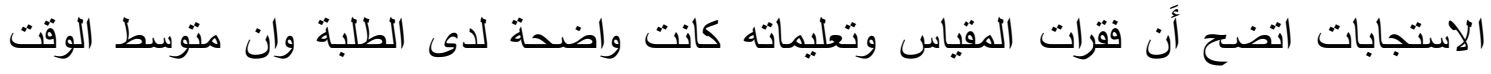

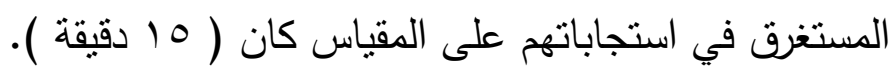

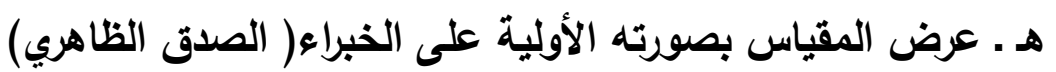
ولغرض التعرف على مدى صلاحية الفقرات ( الصدق الظاهري ) عرض الباحث المقياس المدئ

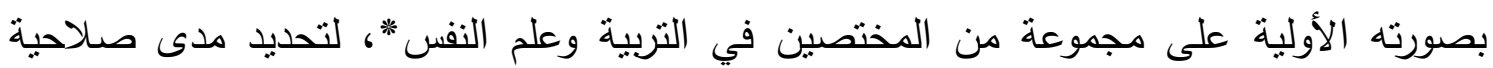

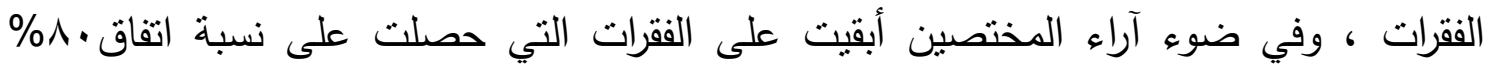

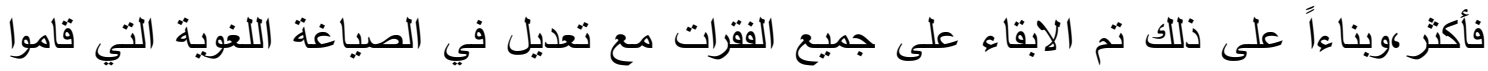

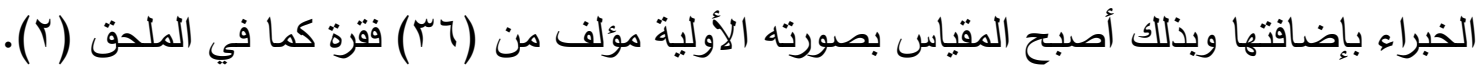

$$
\begin{aligned}
& \text { * أسماء الخبراء } \\
& 1 \text { ا. ا.د. حيدر كريم سكر لئهر } \\
& \text { r ـ ا.د. نبيل عبد الغفور } \\
& \text { r ا ا.د. .محمد سعود صغير } \\
& \text { ع ـ ا.م.د أمل اسماعيل عايز } \\
& \text { هـ ا.د. لمياء ياسين }
\end{aligned}
$$

و. عينة التحليل الإحصائي للفقرات: نتشير نانلي( Nunnaly ) الى أن حجم عينة التمييز

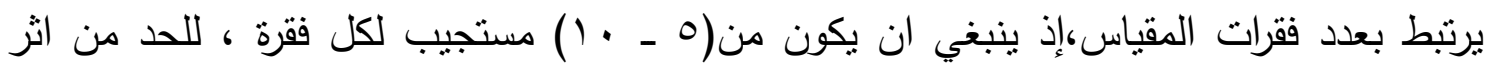

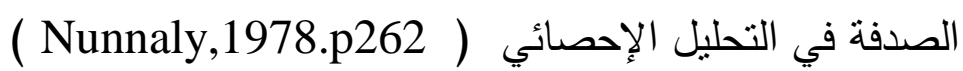

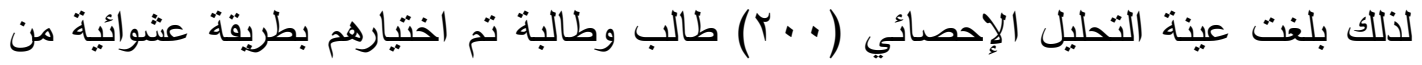

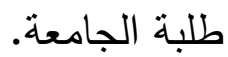
ي ـ القوة التمييزية: الهدف من هذه الإجراءات في تحليل الفقرات الإبقاء على الفقرات المميزة

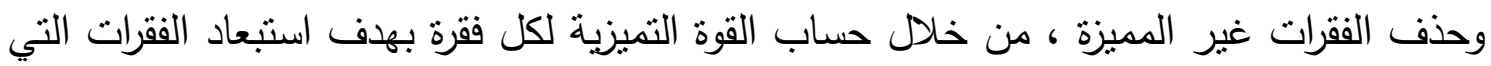


لا تميز بين المستجيبين والإبقاء على الفقرات التي تميز بينهم وقد تمت هذه الإجراءات على وفق ما يأتي : ـ أسلوب المجموعتين المتطرفتين: لغرض أجراء التحليل بهذا الأسلوب تم أتباع الخطوات

(. قام الباحث بتصحيح كل استمارة وإعطاء كل فقرة درجة وبحسب نوعها (ايجابي/ سلبي) r. تحديد الدرجة الكلية لكل استمارة وبحسب مجموع درجات الفقرات

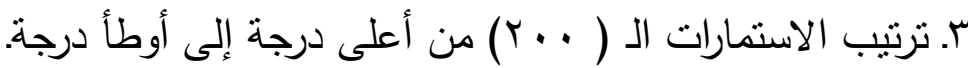

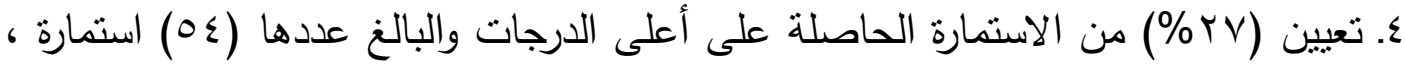

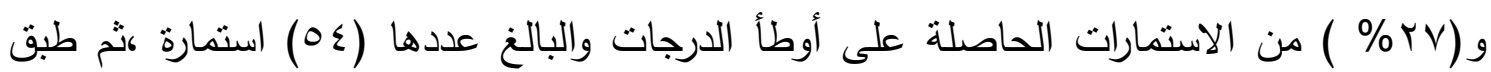
الاختبار التائي لعينتين مستقلتين لاختبار الفرق بين منوسط درجات الهجموعة العليا والمجموعة

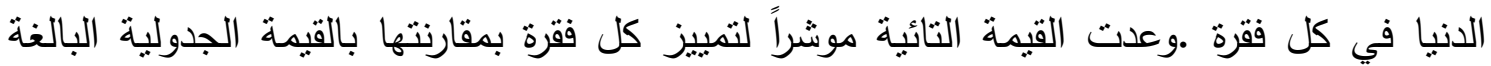
(1,97) وقد كانت الفقرات جميعها مميزة عند مستوى دلالة (.0.,·) وبذللك أصبح المقياس

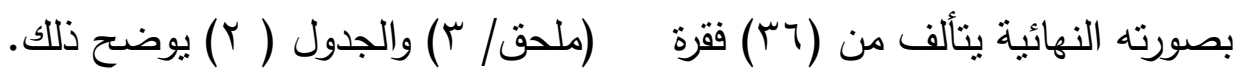

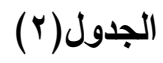

القوة التمييزية لمقياس الثعور بالنقص

\begin{tabular}{|c|c|c|c|c|c|}
\hline \multirow[t]{2}{*}{ القيمة التائية المحسوبة } & \multicolumn{2}{|r|}{ المجموعة الدنيا } & \multicolumn{3}{|c|}{ المجموعة العليا } \\
\hline & الاتحراف المعياري & المتوسط الحسابي & الاتحراف المعياري & المتوسط الحسابي & $ت$ \\
\hline $0, \wedge \wedge$ & $1,1 V$ & $r, r)$ & $\left.\cdot,{ }^{\wedge}\right)$ & $\{, \xi\rceil$ & 1 \\
\hline 0,91 & $1, r$. & r, Yo & $\cdot, \mathrm{V} \leq$ & $\varepsilon, \varepsilon$ & $Y$ \\
\hline $7, \cdot r$ & $1, r r$ & $Y, V V$ & $\cdot, 9 \leqslant$ & $\varepsilon, 0$ & $r$ \\
\hline 1,99 & $1, r r$ & $r, \leqslant$. & 1,11 & $r, q 1$ & $\varepsilon$ \\
\hline$\{, \xi q$ & $1, r v$ & r,^o & 1,11 & $r, 79$ & 0 \\
\hline$\varepsilon, 1 V$ & $1, r q$ & $r, \wedge r$ & $1, Y Y$ & $r, \wedge \wedge$ & 7 \\
\hline$V, r r$ & $1, r r$ & $r, V V$ & $\cdot, \wedge 0$ & $\varepsilon, r_{0}$ & $\mathrm{~V}$ \\
\hline $7, r V$ & $1, r V$ & $r, \wedge r$ & $\cdot, 94$ & $\varepsilon, Y_{\cdot}$ & $\Lambda$ \\
\hline$\varepsilon, 1$ & $1, \leqslant Y$ & $r, r q$ & $\cdot, 9 \mathrm{~V}$ & $\varepsilon, Y_{0}$ & 9 \\
\hline $7, r \leq$ & $1, r Y$ & $Y, V Y$ & $\cdot, \wedge \mathrm{V}$ & $\varepsilon, .9$ & 1. \\
\hline 0,09 & $1, \leqslant r$ & $r, \wedge \vee$ & 1,00 & $r, q \wedge$ & 11 \\
\hline$\Lambda, 7 \Lambda$ & $1, \cdot 1$ & $r, 71$ & $\cdot, 94$ & $\varepsilon, Y \varepsilon$ & IY \\
\hline $7,9 Y$ & $1, r q$ & $r, V Y$ & $\cdot, q 4$ & $\xi, Y Y$ & $1 \pi$ \\
\hline $9, \ldots 7$ & 1,19 & $r, \cdot V$ & 1,1 & $\varepsilon, 0$ & $1 \leq$ \\
\hline $1 Y, 11$ & 1,11 & $r, \cdot 0$ & $\cdot, \mathrm{V \Lambda}$ & $\varepsilon, \xi$ & 10 \\
\hline$\varepsilon, 0 V$ & $1,0 \mathrm{~V}$ & $r, 79$ & 1,11 & $r, \wedge \vee$ & 17 \\
\hline $0, \leqslant Y$ & $1, \varepsilon$ & $r, 11$ & $1, Y 0$ & $r, o v$ & IV \\
\hline$\Lambda,+1$ & 1,10 & $1,9$. & $1,1 \mathrm{~V}$ & $r, v \cdot$ & 11 \\
\hline $7, Y 7$ & $1,1 \varepsilon$ & $r, \leqslant 7$ & $1,1 Y$ & $r, \wedge r$ & 19 \\
\hline$\varepsilon, \mu v$ & $1,{ }^{4}$ & $r, 71$ & $1, \gamma \wedge$ & $\uparrow, 7 \wedge$ & $r$. \\
\hline$\Lambda, \cdot \varepsilon$ & $1,+1$ & $r, r \cdot$ & $1,1 \pi$ & $r, \wedge \vee$ & YI \\
\hline
\end{tabular}




\begin{tabular}{|c|c|c|c|c|c|}
\hline$v, \cdot 9$ & $1,1 \leq$ & $r, r 1$ & 1,11 & $r, q$. & YY \\
\hline $0,9 \mathrm{~V}$ & $1, r^{9}$ & $r, 71$ & 1,11 & $\varepsilon, \cdot r$ & $r T$ \\
\hline$v, 10$ & 1,97 & $r,{ }^{\prime}$ & 1,17 & $r, 74$ & $Y \varepsilon$ \\
\hline$\Lambda, 7 \wedge$ & 1,11 & $r, \cdot r$ & $1, r \mu$ & $\varepsilon, \bullet$ & ro \\
\hline$q, \cdot r$ & 1,01 & $r, \varepsilon \cdot$ & $\cdot, V_{1}$ & $\leqslant, \leqslant 7$ & Y4 \\
\hline$r, \leqslant 0$ & $1,7 \leqslant$ & $r, \wedge V$ & $1, r q$ & $r, 0 q$ & $Y V$ \\
\hline$V,{ }^{\prime}, Y$ & $1, r q$ & $r, 01$ & 1,9 & $\varepsilon, Y \xi$ & $r \Lambda$ \\
\hline$\Lambda, 01$ & 1,11 & 1,100 & $1, r \wedge$ & $r, v$. & rq \\
\hline $1 \cdot, \wedge 7$ & 1,11 & $r, r$. & $\cdot, 9$. & $\varepsilon, \xi$ & $r$. \\
\hline$\Lambda, \wedge \bullet$ & $1, r \Delta$ & $r, r v$ & $\cdot, 91$ & $\varepsilon, r r$ & $M$ \\
\hline$v, r_{0}$ & $1, r \wedge$ & $r, \varepsilon=$ & 1,10 & $\varepsilon, 1 Y$ & rY \\
\hline 9,71 & $1, r_{0}$ & $r, \varepsilon \cdot$ & $\cdot, \wedge r$ & $\varepsilon, \mu \wedge$ & $r r$ \\
\hline $9, Y_{0}$ & $1, r^{9}$ & $Y, V \varepsilon$ & $\cdot, \mathrm{V} \cdot$ & $\varepsilon, 7 \leqslant$ & $r \varepsilon$ \\
\hline 14,11 & $1, \cdot r$ & $r, .9$ & $\cdot, 91$ & $\varepsilon, r V$ & ro \\
\hline$\Lambda, q 1$ & $1,1 Y$ & $r, \cdot 1$ & $1, r$. & $\varepsilon, \cdot 1$ & $r$ \\
\hline
\end{tabular}

\section{ـ علاقة الفقرة بالدرجة الكلية}

لقد استعمل معامل ارتباط بيرسون لاستخراج العلاقة الارتباطية بين درجة كل فقرة من فقرات

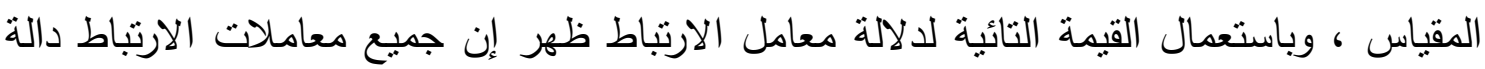

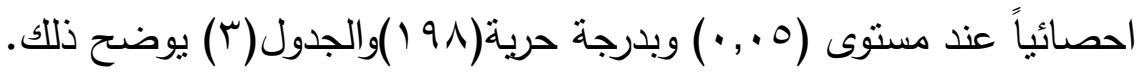

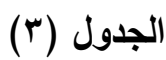

معاملات ارتباط فقرات مقياس الشعور بالنقص بالارجة الكلية

\begin{tabular}{|c|c|c|c|}
\hline معامل الارتباط & $ت$ & معامل الارتباط & ت \\
\hline$\cdot, \leqslant 0$ & 19 & $\cdot, \varepsilon Y$ & 1 \\
\hline$\cdot, \mu \xi$ & $r$. & $\cdot, \leqslant \mathrm{V}$ & $r$ \\
\hline •, & r & $\cdot, \leqslant \wedge$ & $\mu$ \\
\hline$\therefore \leqslant \wedge$ & rr & r, rr & $\varepsilon$ \\
\hline$\cdot, \leqslant 9$ & rT & $\cdot, r q$ & 0 \\
\hline$\cdot, \leqslant \leqslant$ & $r \varepsilon$ & $\cdot, \ldots$ & 7 \\
\hline$\cdot, 09$ & ro & $\cdot, 0 Y$ & $\mathrm{v}$ \\
\hline$\cdot, 0 \mathrm{~V}$ & it & $\cdot, 0 \leqslant$ & $\Lambda$ \\
\hline$\cdot, \mathrm{YA}$ & $T V$ & 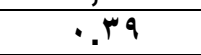 & 9 \\
\hline$\cdot, \leqslant \mathrm{V}$ & $Y \Lambda$ & $\cdot, \leqslant \wedge$ & 1. \\
\hline$\cdot, 0 Y$ & rq & $\cdot, \xi$ & 11 \\
\hline$\cdot, \mathrm{TV}$ & $r \cdot$ & $\cdot, 07$ & IT \\
\hline$\cdot, 7 \varepsilon$ & $\mu$ & $\cdot, \leqslant \leqslant$ & it \\
\hline$\cdot, \leqslant 9$ & $r r$ & $\cdot, 71$ & $1 \leqslant$ \\
\hline$\cdot, \pi$ & $r T$ & $\cdot, 0 \wedge$ & 10 \\
\hline$\cdot, 09$ & $\Gamma \leqslant$ & $\cdot, r \cdot$ & 17 \\
\hline$\cdot, 79$ & ro & . , rq & IV \\
\hline$\cdot, 0 Y$ & 4 & $\cdot, O Y$ & 11 \\
\hline
\end{tabular}

علاقة درجة الفقرة بدرجة المكون ا:

استخدم الباحث هذا الأسلوب للتتبت من أَن فقرات كل مكون تعبر عنه ولتحقيق ذلك اعتد

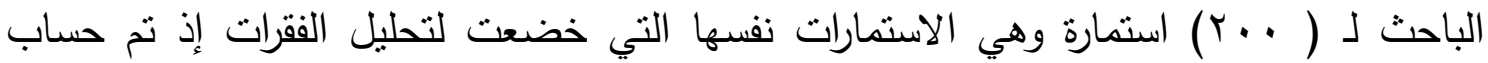


الدرجة الكلية لهؤلاء الإفراد على وفق مكونات المقياس الاربعة ثم استعمل معامل ارتباط بيرسون لحساب معامل الارتباط بين درجات هؤلاء الأفراد على كل فقرة والدرجة الكلية للمكون الذي توجد

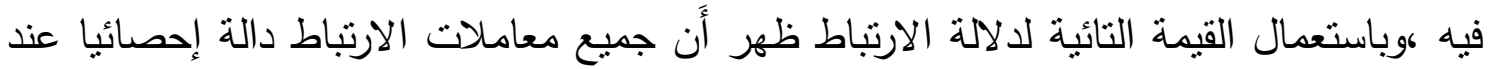

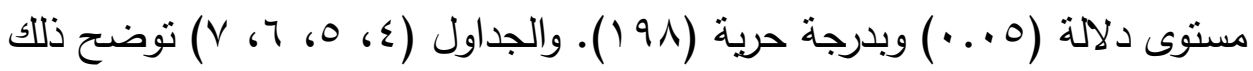

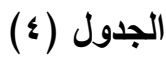

معاملات ارتباط درجة كل فقرة بالارجة الكلية لمجال ضعف الثقة بالنفس الأبس

\begin{tabular}{|c|c|c|c|c|c|}
\hline معامل الارتباط & الفقرة & معامل الارتباط & الفقرة & معامل الارتباط & الفقرة \\
\hline$\cdot, r q$ & $v$ & $\cdot, \leqslant V$ & $\varepsilon$ & $\cdot, \leqslant r$ & 1 \\
\hline$\cdot, \leqslant Y$ & $\Lambda$ &., 00 & 0 & 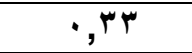 & $r$ \\
\hline$\cdot, \leqslant V$ & 9 & , \&1 & 7 & $\cdot, \leqslant 0$ & $r$ \\
\hline
\end{tabular}

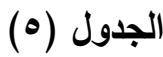

معاملات ارتباط درجة كل فقرة بالارجة الكلية لمجال الخجل في المواقف الاجتماعية

\begin{tabular}{|c|c|c|c|c|c|}
\hline معامل الارتباط & الفقرة & معامل الارتباط & الفقرة & معامل الارتباط & الفقرة \\
\hline$\cdot, \ldots$ & 17 & $\cdot, \leqslant 0$ & $1 \pi$ & $\cdot, r r$ & 1. \\
\hline$\cdot, \leqslant 1$ & IV & $\cdot, 0 Y$ & $1 \varepsilon$ & $\cdot, \leqslant 1$ & 11 \\
\hline$\cdot, \leqslant \leqslant$ & 11 & $\cdot, \leqslant 7$ & 10 & $\cdot, r q$ & Tr \\
\hline
\end{tabular}

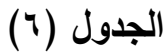

معاملات ارتباط درجة كل فقرة بالدرجة الكلية لمجال ضعف القدرة في اتخاذ القرار

\begin{tabular}{|c|c|c|c|c|c|}
\hline معامل الارتباط & الفقرة & معامل الارتباط & الفقرة & معامل الارتباط & الفقرة \\
\hline$\cdot, \leqslant \wedge$ & ro & $\cdot, \leqslant \mu$ & YY & $\cdot, \leqslant \leqslant$ & 19 \\
\hline$\cdot, r q$ & YT & $\cdot, 01$ & rr & $\cdot, r q$ & $r \cdot$ \\
\hline$\cdot, \leqslant 9$ & $Y V$ & $\cdot, \leqslant 1$ & $Y \varepsilon$ & $\cdot, \leqslant 7$ & YI \\
\hline
\end{tabular}

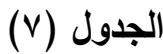

معاملات ارتباط درجة كل فقرة بالارجة الكلية لمجال الكفاح من اجل التفوق والكمال

\begin{tabular}{|c|c|c|c|c|c|}
\hline معامل الارتباط & الفقرة & معامل الارتباط & الفقرة & معامل الارتباط & الفقرة \\
\hline$\cdot, \leqslant \leqslant$ & $r \leqslant$ & $\cdot, \mu v$ & r & $\cdot, r v$ & $r \wedge$ \\
\hline$\cdot, \leqslant \wedge$ & ro &.,$\leqslant 1$ & rr & $\cdot, \leqslant Y$ & rq \\
\hline$\cdot, \leqslant 1$ & 49 & $\cdot, r 0$ & $r r$ & $\cdot, 0$. & $r$. \\
\hline
\end{tabular}

الخصائص السايكومترية للمقياس:

الصدق Validity: يعد الصدق من الخصائص الأساسية في بناء المقاييس التربوية والنفسية وقد تم تحقق من مؤشرين للصدق هما: اـ الصدق الظاهري Face Validity: تم تحقيق هذا النوع من الصدق في المقياس الحالي عندما عرضت فقراته على مجموعة من الخبراء والمختصين في التربية وعلم النفس كما مشار اليه سابقاً. r_ صدق البناء أو أي ظاهرة سلوكية معينة وبهتم هذا النوع من الصدق بطبيعة الظاهرة التي يقيسها المقياس أي 
مدى تضمينه بناءً نظرياً محدداً أو صفة معينة وقد تم استخراج مؤشرات تدل على هذا الصدق من خلال علاقة الفقرة بالدرجة الكلية. حيث يعد معامل الارتباط بين درجة الفقرة والدرجة الكلية مؤشراً لصدق البناء وعلاقة درجة الفقرة بدرجة المكون. الثبات Reliability: ونم إيجاد ثبات مقياس الثعور بالنقص بطريقتن هما :

$$
\text { 1- إعادة الاختبار ( Test - Re-test) }
$$

في الدراسة الحالية قام الباحث بتطبيق مقياس الثعور بالنقص على عينة بلغت (Vo) طالبًا وطالبة نم اختيارهم بطريقة عشوائية ،وأعيد نطبيق المقياس على العينة نفسها بعد مرور (أسبوعين)

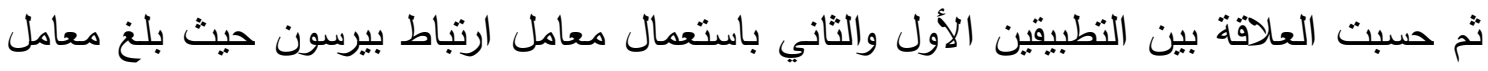

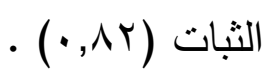

r- بادلة الفاكرونباخ ( Alfacrnbach) استخرج معامل الاتساق الداخلي لمقياس الثعور بالنقص باستعمال معادلة الفاكرونباخ لارجات افراد العينة وبلغ معامل الثبات (10, · • ). ثانياً : مقياس معنى الحياة تحقيقا لأهداف البحث قام الباحث ببناء مقياس معنى الحياة وذلك وفقاً للإطار النظري الذي

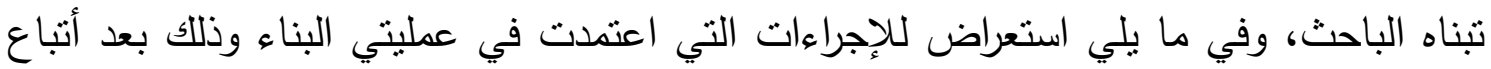

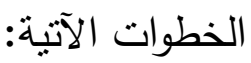
أ. تحديد تعريف مفهوم معنى الحياة: قام الباحث بالاطلاع على الإطار النظري للموضوع

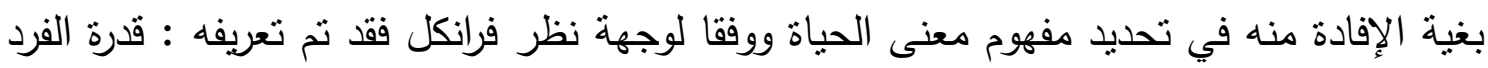

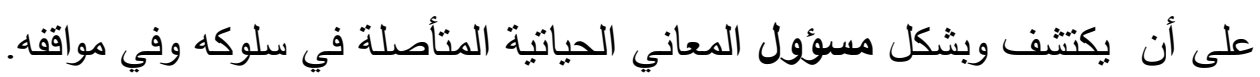

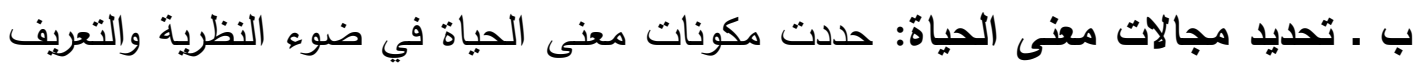
المتبناة وقد حدد في ثلاث مكونات وهي: ا. الانجاز : هو انجاز الفرد للإعمال من خلال القيام بالنشاطات في المحيط الذي ينتمي أليه كالعمل الذي يزاوله ،وتلبيته حاجاته وحاجات أسرته والإبداع في المجال التهال العلمي. r. الوجود :وهو قدرة الفرد في تحقيق المعنى في الوجود من خلال أدرالك الفرد لمعنى وجوداته والتمتع بجمالية الحياة وطبيعتها وأواصر العلاقات مع الآخرين والحب والتعائ التعاون.

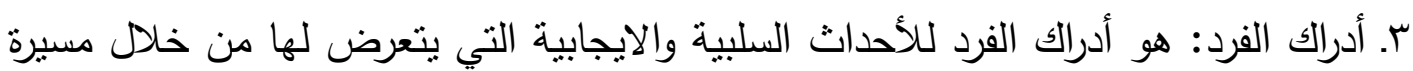

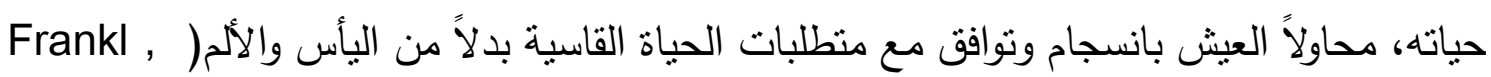
.(1964, P.112 


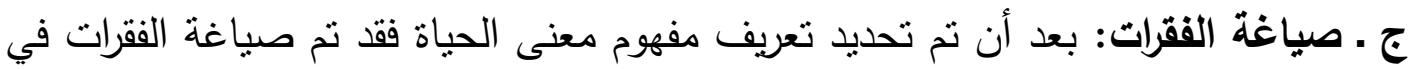
ضوء التعريف المشار إليه أعلاه وقد روعي في صياغة الفرات الفقرات أَن تكون مفهومة، وقابلة لتفسير

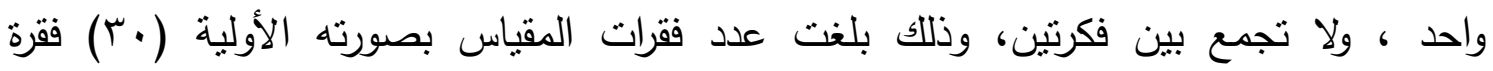
والملحق(ع) يوضح ذللك.

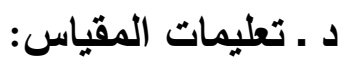

لغرض التعرف على وضوح تعليمات المقياس ووضوح فقراته وبدائله فضلا عن الكثف عن

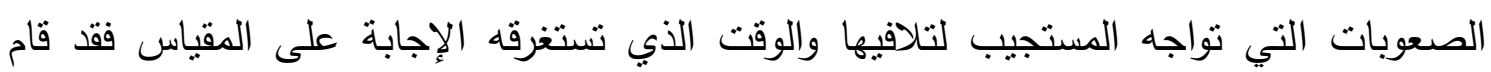

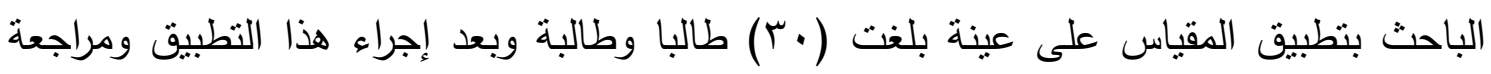

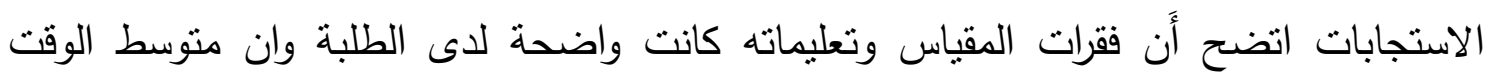
المستغرق في استجاباتهم على المقياس كان (· ب دقيقة ).

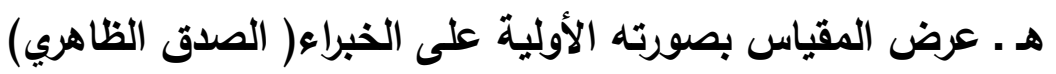

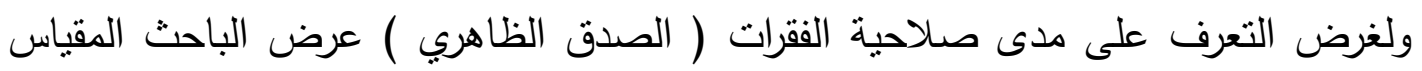

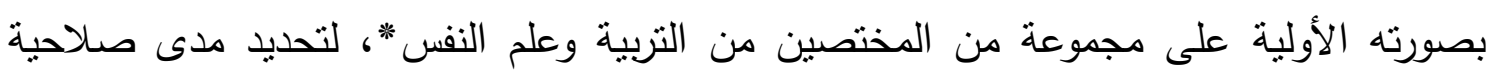

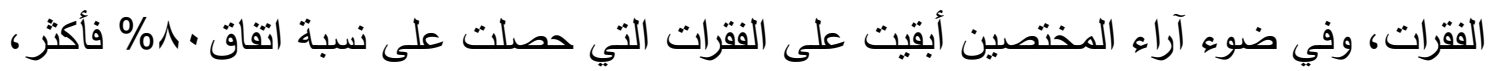
وبناءً على ذلك تم الإبقاء على جميع الفقرات مع تعديل في الصياغة اللغوية التي قاموا الخبراء

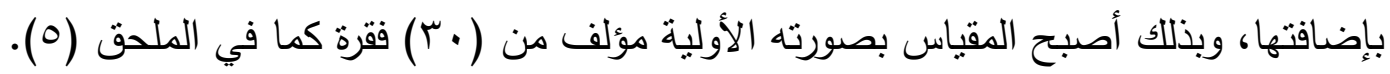

$$
\begin{aligned}
& \text { * أسماء الخبراء } \\
& \text { I ا.د.. حيدر كريم سكر } \\
& \text { r ـ ا.د. نبيل عبد الغفور }
\end{aligned}
$$

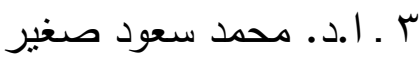

$$
\begin{aligned}
& \text { ـ ـ ا.م.د. أمل عايز } \\
& \text { ه ـ ا.د. لمياء ياسين } \\
& \text { و. عينة التحليل الإحصائي للفقرات: }
\end{aligned}
$$

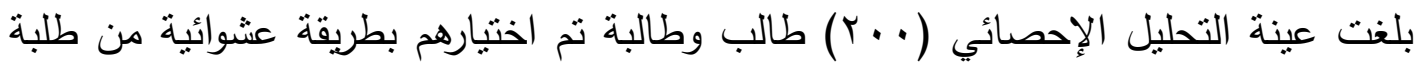

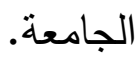

ي ـ القوة التمييزية: الهدف من هذه الإجراءات في تحليل الفقرات الإبقاء على الفقرات المميزة

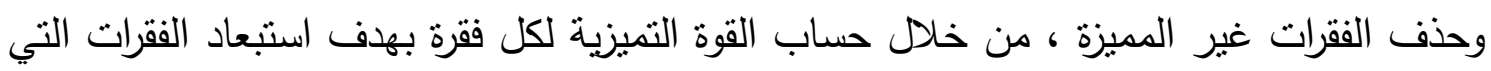
لا تميز بين المستجييين والإبقاء على الفقرات التي تميز بينهم. طبق الاختبار التائي لعينتين 
مستقلتين لاختبار الفرق بين متوسط درجات المجموعة العليا والمجموعة الدنيا في كل فقرة .وعدت القيمة التائية مؤشراً لتمييز كل فقرة بمقارنتها بالقيمة الجدولية البالغة (T9, 1) وقد كانت الفقرات جميعها مميزة عند مستوى دلالة (0., • ) وبذلك أصبح المقياس بصورته النهائية يتألف من (. (؟) فقرة ملحق (†) والجدول ( ^) يوضح ذلك. (^) الجدول(^)

القوة التمييزية لمقياس معنى الحياة

\begin{tabular}{|c|c|c|c|c|c|}
\hline \multirow[b]{2}{*}{ القيمة التائية المحسوبة } & \multicolumn{2}{|r|}{ المجموعة الدنيا } & \multicolumn{3}{|c|}{ المجموعة العليا } \\
\hline & الانحراف المعياري & المتوسط الحسابي & الانحراف المعياري & المتوسط الحسابي & ت \\
\hline $9, \cdot 1$ & $\cdot, 7 \Lambda$ & $r, .0$ & $\cdot, \wedge$. & $\varepsilon, r_{0}$ & 1 \\
\hline $1 \cdot, r v$ & $1, \cdot 1$ & 1,100 & $1, \leqslant 0$ & $r, r_{O}$ & $\bar{r}$ \\
\hline$\varepsilon, \cdot 1$ & $1, \cdot 0$ & $Y, 01$ & $1, r \varepsilon$ & $r, \leqslant 4$ & $r$ \\
\hline 7,10 & 1,04 & $r, \wedge 0$ & $\cdot, \times 1$ & $\varepsilon, \xi$. & $\varepsilon$ \\
\hline$\Lambda, \cdot Y$ & $1, \cdot \varepsilon$ & $1, \wedge \wedge$ & $1, r^{2}$ & $r, 7 \leqslant$ & 0 \\
\hline $1 \%, 11$ & $1,1 V$ & 1,94 & $\cdot, \wedge \varepsilon$ & $\varepsilon, \pi$ & 7 \\
\hline $1 \cdot, 1 \leqslant$ & $1, \cdot 1$ & $r, \cdots$ & $1, \cdot \varepsilon$ & $\varepsilon, \cdot V$ & $\mathrm{v}$ \\
\hline 9,99 & $1, r \cdot$ & $Y, \leqslant \leqslant$ & $\cdot, \wedge \Gamma$ & $\varepsilon, \leqslant \leqslant$ & $\Lambda$ \\
\hline$v, \xi 1$ & $1,0 \mathrm{~V}$ & $r, 71$ & $\cdot$, , $\mathrm{T}$ & $\varepsilon, \xi \cdot$ & 9 \\
\hline $1+1$. & 1,17 & $r, 1 Y$ & $\cdot, \mathrm{V} \varepsilon$ & $\varepsilon, 09$ & 1. \\
\hline 9,7 & $1, r_{0}$ & $r, \cdots$ & 1,14 & $\varepsilon, Y \leqslant$ & 11 \\
\hline $0, \wedge 1$ & 1,14 & $Y, \leqslant 4$ & $1, Y \wedge$ & $\Gamma, \wedge \Gamma$ & IY \\
\hline 7,01 & $1, r \leqslant$ & $r, Y V$ & $1,1 \pi$ & $\varepsilon, r r$ & ir \\
\hline 9,14 & 1,14 & $1,9$. & 1,11 & $r, 91$ & $1 \leq$ \\
\hline$v, \wedge$. & 1,17 & $1,9$. & • & $\varepsilon, \mu$ & 10 \\
\hline$r, q r$ & 1,44 & $r, 00$ & $\cdot, \wedge 1$ & $\xi, \xi \cdot$ & 17 \\
\hline $0, \leqslant \leqslant$ & $1,0$. & $r, 01$ & $1, Y \wedge$ & $r, 91$ & IV \\
\hline $7, \cdot \mathrm{V}$ & $1, \cdot 1$ & $r, r V$ & $\cdot, \mathrm{VN}$ & $\varepsilon, r_{0}$ & 11 \\
\hline 9,14 & 1,11 & $Y, V Y$ & $\cdot, \mathrm{Va}$ & $\varepsilon, 0$. & 19 \\
\hline$v, 0 \leqslant$ & $1, r q$ & $Y, T \leqslant$ & $\cdot, \wedge 9$ & $\varepsilon, Y_{O}$ & r. \\
\hline $7,9 \mathrm{~V}$ & $1, Y \wedge$ & $r, \xi$. & $1,1 \mathrm{~V}$ & $\varepsilon, \cdot 0$ & Y) \\
\hline $1 \cdot, 09$ & $1, \cdot v$ & r,or & ., $\mathrm{4}$ & $\varepsilon, \leqslant \varepsilon$ & rr \\
\hline$v, \leqslant 0$ & $1, \pi 1$ & $r, V_{0}$ & $\cdot, 91$ & $\varepsilon, r \wedge$ & YT \\
\hline $11,7 \leqslant$ & 1,11 & $Y, \cdot V$ & $\cdot, 9 \mathrm{~V}$ & $\varepsilon, r_{0}$ & $r \leqslant$ \\
\hline $1 \cdot, \mathrm{rv}$ & $1, Y \wedge$ & $Y, Y \leqslant$ & $\cdot, \wedge 1$ & $\varepsilon, \Gamma \wedge$ & ro \\
\hline $0, \pi 1$ & $1, \leqslant 9$ & $r, \cdot v$ & $\cdot, \wedge$. & $\varepsilon, \mathrm{rV}$ & Y4 \\
\hline $1 \Gamma, \leqslant \wedge$ & $\cdot, 90$ & $1, \wedge 0$ & $\cdot, \wedge 9$ & $\varepsilon, Y_{0}$ & YV \\
\hline 7,70 & $1, \cdot r$ & $r, I r$ & 1,19 & $r, 00$ & YA \\
\hline$\Lambda, 10$ & $1, \cdot 1$ & $r, Y \leqslant$ & 1,11 & $r, 94$ & ra \\
\hline$\varepsilon, V_{0}$ & $1, r \wedge$ & $Y, \leqslant Y$ & $1, Y \leqslant$ & $r, T r$ & $r$. \\
\hline
\end{tabular}

ـ علاقة الفقرة بالدرجة الكلية: لقد استعمل معامل ارتباط بيرسون لاستخراج العلاقة الارتباطية بين درجة كل فقرة من فقرات المقياس، وباستعمال القيمة التائية لدلالة معامل الارنباط ظهر إن جميع معاملات الازتباط دالة احصائياً عند مستوى (0.,•) وبدرجة حرية(19 ()) والجدول(9) يوضح ذلك.

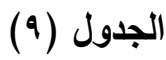


معاملات ارتباط فقرات مقياس معنى الحياة بالدرجة الكلية

\begin{tabular}{|c|c|c|c|}
\hline معامل الارتباط & $ت$ & معامل الارتباط & ت \\
\hline$\cdot, Y q$ & 17 & $\cdot, 0$. & 1 \\
\hline$\cdot, \leqslant \mu$ & IV & $\cdot, 70$ & $r$ \\
\hline$\cdot, r q$ & 11 & $\cdot, r \Delta$ & $r$ \\
\hline$\cdot, 09$ & 19 & $\cdot, \leqslant 9$ & $\varepsilon$ \\
\hline$\cdot, 0 Y$ & $r \cdot$ & $\cdot, 0 \leqslant$ & 0 \\
\hline$\cdot, \leqslant 0$ & YI & $\cdot, 7 \leqslant$ & 7 \\
\hline . & ry & $\cdot, 09$ & V \\
\hline$\cdot, O Y$ & rT & $\cdot, 74$ & $\Lambda$ \\
\hline$\cdot, 7 \mathrm{~V}$ & $r \leqslant$ & $\cdot, 0 r$ & 9 \\
\hline$\cdot, T r$ & ro & $\cdot, v_{1}$ & 1. \\
\hline$\cdot, \leqslant \Gamma$ & rq & $\cdot, 7$. & 11 \\
\hline $.7 \mathrm{~V}$ & $r V$ & $\cdot, \varepsilon r$ & Ir \\
\hline$\cdot, \leqslant V$ & $r \wedge$ & $\cdot, \leqslant 0$ & 14 \\
\hline$\cdot, 01$ & rq & $\cdot, 0 \wedge$ & $1 \leq$ \\
\hline$\cdot, r \varepsilon$ & $r \cdot$ & $\cdot, 0 r$ & 10 \\
\hline
\end{tabular}

علاقة درجة الفقرة بلرجة المكون: استخدم الباحث هذا الأسلوب للتنبت من أَن فقرات كل مكون تعبر عنه ولتحقيق ذلك اعتمد الباحث لـ( . . استمارة وهي الاستمارات نفسها التي خضعت لتحليل الفقرات إذ تم حساب الدرجة الكلية لهؤلاء الإفراد على وفق مكونات المقياس الثلاثة ثم استعمل معامل ارتباط بيرسون لحساب معامل الارتباط بين درجات هؤلاء الأفراد على كل فقرة والدرجة الكلية للمكون الذي توجد فيه ،وباستعمال القيمة التائية لدلالة الارتباط ظهر أَن جميع

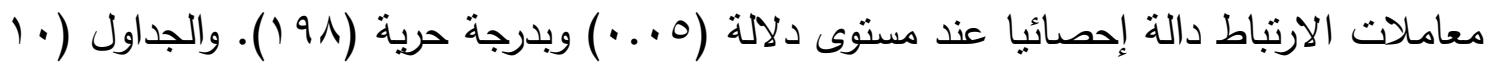

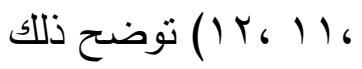

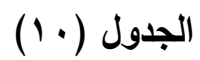

معاملات ارتباط درجة كل فقرة بالدرجة الكلية لمكون الانجاز

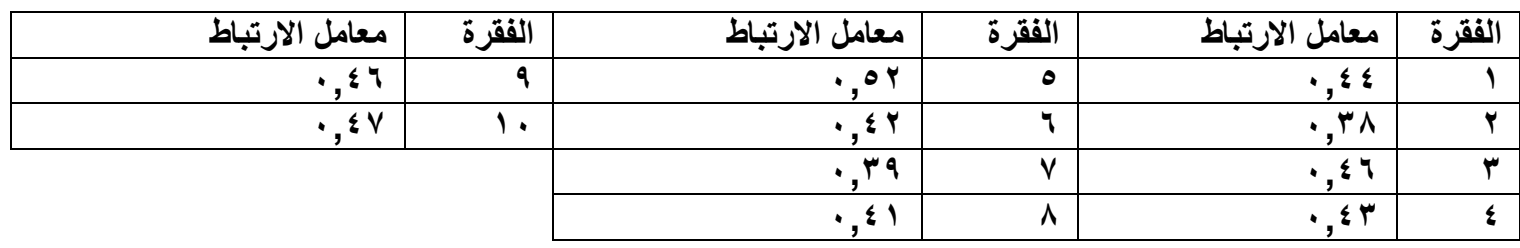

(الجدول (11)

معاملات ارتباط درجة كل فقرة بالدرجة الكلية لمكون الوجود

\begin{tabular}{|c|c|c|c|c|c|}
\hline معامل الارتباط & الفقرة & معامل الارتباط & الفقرة & معامل الارتباط & الفقرة \\
\hline$\cdot, \mu v$ & 19 & $\cdot, r q$ & 10 & $\cdot, \leqslant \leqslant$ & 11 \\
\hline$\cdot, \leqslant 1$ & $r$. & $\cdot, \xi$ & 17 & $\cdot, \leqslant 1$ & IY \\
\hline & & $\cdot, r q$ & IV & $\cdot, r r$ & 14 \\
\hline & & $\cdot, \leqslant 0$ & 11 & $\cdot, \leqslant 0$ & $1 \varepsilon$ \\
\hline
\end{tabular}




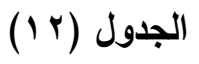

معاملات ارتباط درجة كل فقرة بالارجة الكلية لمكون أدراك الفرد

\begin{tabular}{|c|c|c|c|c|c|}
\hline معامل الارتباط & الفقرة & معامل الارتباط & الفقرة & معامل الارتباط & الفقرة \\
\hline$\cdot, 0$. & rq & $\cdot, \leqslant 0$ & ro & $\cdot r v$ & YI \\
\hline$\cdot, \mu$ & r. & $\cdot, \leqslant \leqslant$ & $r q$ & $\cdot, \leqslant 01$ & rY \\
\hline & & $\cdot, \leqslant 1$ & TV & $\cdot, r q \mu$ & YT \\
\hline & & $\cdot, \Delta \vee \wedge$ & FA & $\cdot, \leqslant 1 \pi$ & Y $\varepsilon$ \\
\hline
\end{tabular}

الخصائص السايكومترية للمقياس:

الصدق Validity: يعد الصدق من الخصائص الأساسية في بناء المقاييس التربوية والنفسية وقد تم تحقق من مؤشرين للصدق هما:

اـ الصدق الظاهري Face Validity: تم تحقيق هذا النوع من الصدق في المقياس الحالي عندما عرضت فقراته على مجموعة من الخبراء والمختصين في التربية وعلم النفس كما مشار إليه

r_ صدق البناء Construct Validity: تم استخراج مؤشرات تدل على هذا الصدق من خلال علاقة الفقرة بالدرجة الكلية. حيث بعد معامل الارتباط بين درجة الفقرة والدرجة الكلية مؤشراً

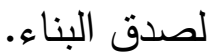
الثبات Reliability: وتم إيجاد ثبات مقياس معنى الحياة بطريقتين هما :

$$
\text { (Test - Re-test ) إعادة الاختبار }
$$

في الدراسة الحالية قام الباحث بتطبيق مقياس معنى الحياة على عينة بلغت ( V0) طالبًا وطالبة تم اختيارهم بطريقة عثوائية ،وأعيد تطبيق المقياس على العينة نفسها بعد مرور (أسبوعين) ثم حسبث العلاقة بين التطبيقين الأول والثاني باستعمال معامل ارتباط بيرسون حيث بلغ معامل الثبات (

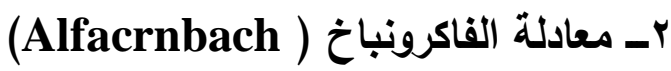
استخرج معامل الاتساق الداخلي لمقياس الثعور بالنقص باستعمال معادلة الفاكرونباخ لدرجات أفراد العينة وبلغ معامل الثبات (1), • ).

التطبيق النهائي: بعد الانتهاء دن إعداد المقياسين بصورتهما النهائية ( الثعور بالنقص ومعنى الحياة ) تم تطبيقهما على إفراد عينة مؤلفة من ( . . . ط) طالب وطالبة، الوسائل الإحصائية : الوب

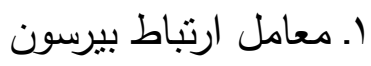
ـ معامل الثبات بطريقة إعادة الاختبار ـ العلاقة بين درجة كل فقرة والدرجة الكلية 
ـ القيمة التائية لدلالة معامل الارتباط. r ـ الاختبار التائي ( T- test) لعينتين مستقلتين ـ القوة التمبيزية لفقرات المقياس r ـ معادلة الفاكرونباخ لاستخراج الثبات لمقياس عرض النتائج وتفسيرها. يتضمن هذا الفصل عرضاً للنتائج التي توصل إليه البحث الحالي على وفق أهدافه المرسومة وتقسير النتائج ، ومن ثم الخروج بتوصيات ومقترحات في ضوء ثلك النتائج أولاً/ عرض النتائج :

ـ الهدف الأول : التعرف على مستوى الثعور بالنقص لاى طلبة الجامعة : أظهرت نتائج

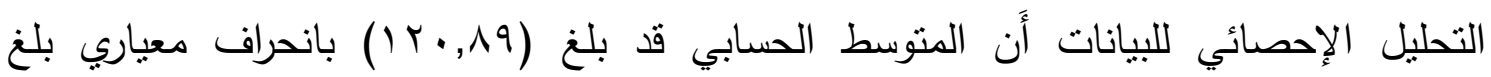

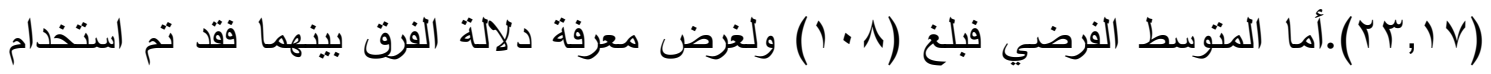
الاختبار التائي لعينة واحدة ، حيث بلغت القيمة التائية المحسوبة (V,AV)وعند مقارنتها مع القيمة الجدولية البالغة ( 97,1 (1) عند مستوى دلالة (0., •) ظهر أَن عينة البحث لديها شعوراً بالنقص أعلى من المتوسط الفرضي. والجدول (r I) يوضح ذللك

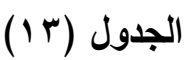

المتوسط الحسابي والانحراف المعياري والوسط الفرضي والقيمة التائية المحسوية والقيمة الجدولية لعينة

\begin{tabular}{|c|c|c|c|c|c|c|}
\hline مستوى الدلالة & القيمة التائية & القيمسة التائية & المترضي & الانحراف & المتوسط الحسابي & العينة \\
\hline دال & 1,97 & $\mathrm{~V}, \wedge \mathrm{V}$ & 1.1 & $r r, I V$ & $1 r \cdot, \wedge q$ & r.. \\
\hline
\end{tabular}

ـ الههف الثاني: التعرف على مستوى معنى الحياة لاى طلبة الجامعة: أظهرت نتائج التحليل الإحصائي للبيانات أَن المتوسط الحسابي قد بلغ (19,Y9) بانحراف معياري بلغ (1,1) (Y) ـ أما المتوسط الفرضيّ؛ فبلغ ( •9) ولغرض معرفة دلالة الفرق بينهما فقد تم استخدام الاختبار التائي لعينة واحدة ، حيث بلغت القيمة التائية المحسوبة (7 ( 7 7) وعند مقارنتها مع القيمة الجدولية البالغة ( 97 , (1) عند مستوى دلالة (0. . • ) ظهر أَن عينة البحث لديها معنى للحياة أعلى من المتوسط الفرضي. والجدول( § ( ) يوضح ذلك

الجدول (؛ 1 )

المتوسط الحسابي والانحراف المعياري والوسط الفرضي والقيمة التائية المحسوية والقيمة الجدولية لعينة الطلبة على الجى مقياس معنى الحياة

\begin{tabular}{|c|c|c|c|c|c|c|}
\hline ه.., مستوى الدلالة & الجديمة التائية & المحسيمة التائية & الفرضيط & الانحيراف & اللعينة & العينة \\
\hline دال & 1,97 & 8,17 & 9. & $r 1,11$ & $99, Y)$ & $r \cdot$. \\
\hline
\end{tabular}


الههف الثالث: التعرف على دلالة الفروق في مستوى الثعور بالنقص لاى طلبة الجامعة

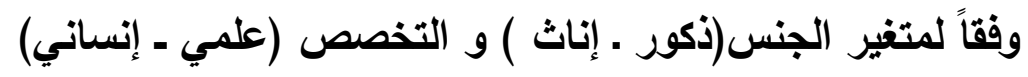
أولاً/ الجنس (ذكور • إناث):

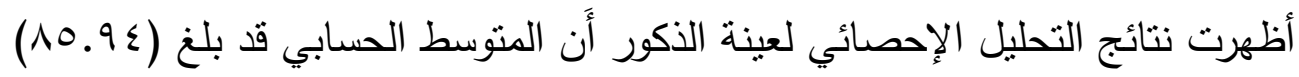

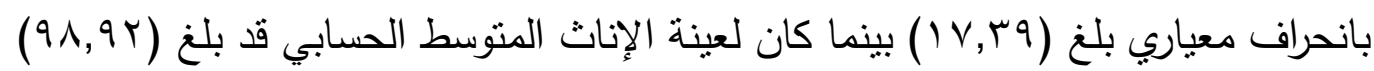

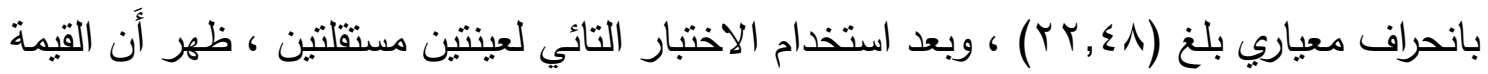

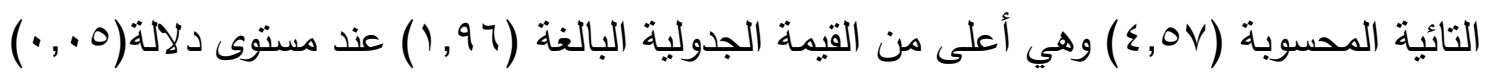

$$
\text { وهي دالة إحصائية. والجدول (10 (10)يوضح ذللك. }
$$

\begin{tabular}{|c|c|c|c|c|c|c|}
\hline \multicolumn{7}{|c|}{ بالنقص } \\
\hline مستوى & القيمة & القيمة & الانحراف & المتوسط & العينة & الجنس \\
\hline الدالة & التائية & التائية & المعياري & الحسابي & & \\
\hline$\cdot, .0$ & الجدولية & المحسوية & & & & \\
\hline \multirow[t]{2}{*}{ دال } & \multirow[t]{2}{*}{1,97} & \multirow[t]{2}{*}{$\varepsilon, \Delta V$} & $1 v, r q$ & $10.9 \leq$ & $1 \ldots$ & ذكور \\
\hline & & & $r Y, \leqslant \Lambda$ & $q \wedge, 94$ & $1 \ldots$ & إناث \\
\hline
\end{tabular}

الاختبار الثائي لاختبار دلالة الفرق بين متوسطي درجات لعينة الجنس (الذكور والإناث)على مقياس الثعور

$$
\text { ثانياً/ التخصص (علمي - إنساني): }
$$

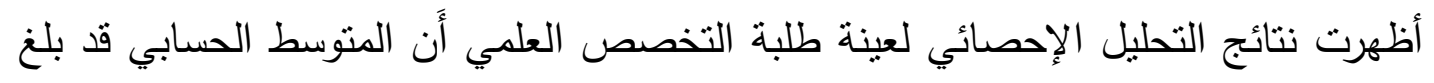

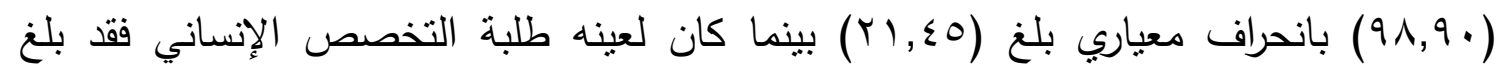

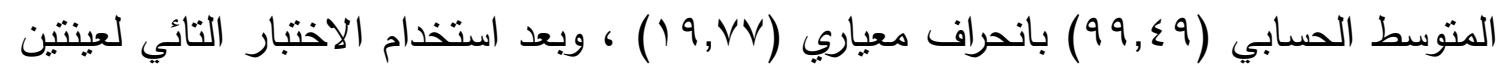

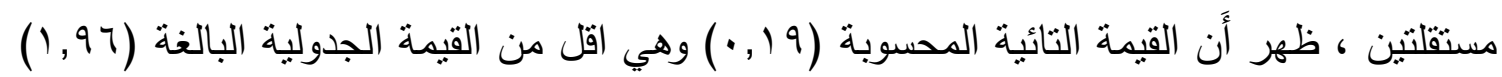

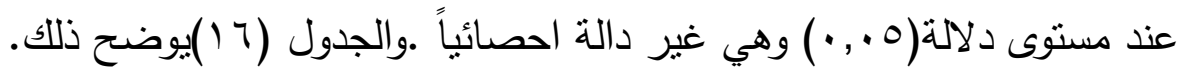

\begin{tabular}{|c|c|c|c|c|c|c|}
\hline \multicolumn{7}{|c|}{ ص } \\
\hline مستوى & القيمة & القيمة & الانحراف & المتوسط & العينة & لتخصص \\
\hline الدالة & التائية & التائية & المعياري & الحسابي & & \\
\hline \multirow{2}{*}{ غير دال } & \multirow[t]{2}{*}{1,94} & \multirow{2}{*}{$\cdot, 19$} & $r, \leqslant 0$ & $9 \wedge, 9$. & $1 \ldots$ & علىى \\
\hline & & & $19, \mathrm{VV}$ & $99, \leqslant 9$ & $1 \ldots$ & إنساني \\
\hline
\end{tabular}
الجدول (14)

الاختبار التائي لاختبار دلالة الفرق بين متوسطي درجات لعينة التخصص (علمي _إنساني)على مقياس

الهلف الرابع: التعرف على دلالة الفروق في مستوى معنى الحياة لاى طلبة الجامعة وفقاً لمتغير الجنس(ذكور - إناث) والتخصص (علمي - إنساني)

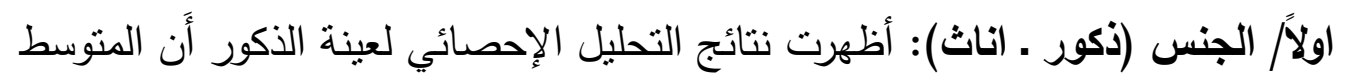

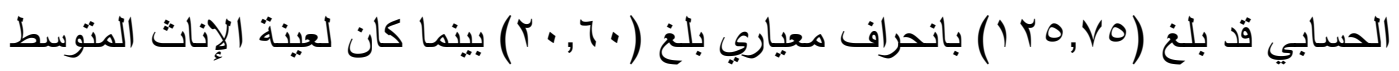




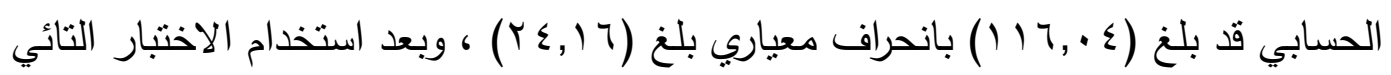

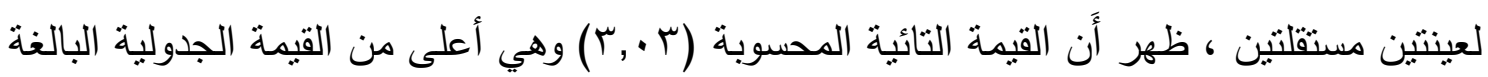

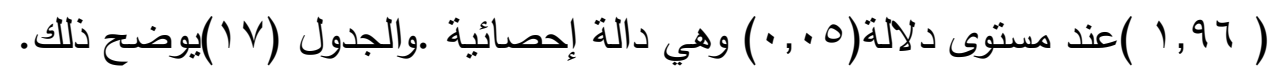

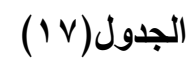

الاختبار التائي لاختبار دلالة القرق بين متوسطي درجات لعينة الجنس (الذكور والإناث)على مقياس مغنى

\begin{tabular}{|c|c|c|c|c|c|c|}
\hline \multicolumn{7}{|c|}{ الحياة } \\
\hline مستوى & القيمة & القيمة & الاححراف & المتوسط & العينة & الجنس \\
\hline الدالة & التائية & التائية & المعياري & الحسابي & & \\
\hline$\cdot, \cdot 0$ & الجدولية & المحسوبة & & & & \\
\hline \multirow[t]{2}{*}{ دال } & \multirow[t]{2}{*}{1,94} & \multirow[t]{2}{*}{$r, \cdot r$} & $r \cdot, r$ & Iro,vo & $1 \ldots$ & ذكور \\
\hline & & & $Y \varepsilon, 14$ & 114,08 & $1 \ldots$ & إناث \\
\hline
\end{tabular}

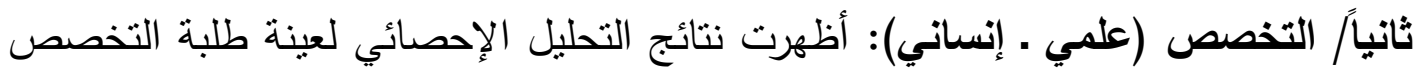

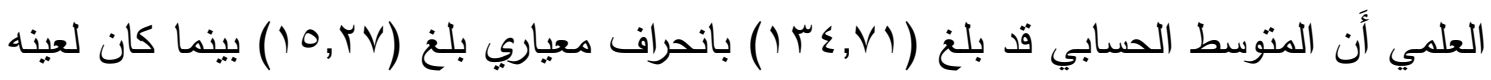

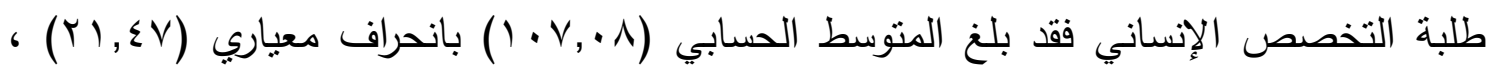

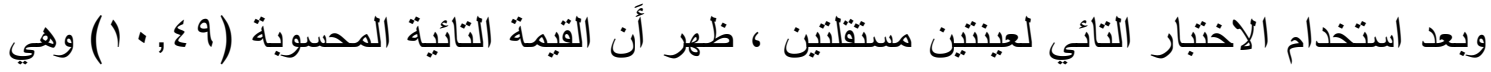

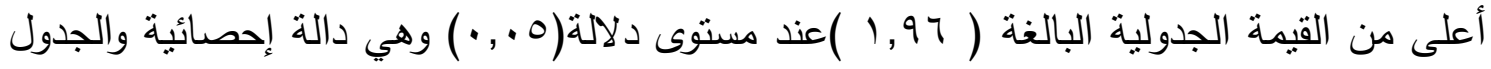

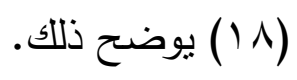

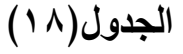

الاختبار التائي لاختبار دلالة الفرق بين متوسطي درجات لعينة التخصص (علمي ـإنساني)على مقياس

\begin{tabular}{|c|c|c|c|c|c|c|}
\hline \multicolumn{7}{|c|}{ معنى الحياة } \\
\hline مستوى & القيمة & القيمة & الانحراف & المتوسط & العينة & التخصص \\
\hline الدالة & التائية & التائية & المعياري & الحسابي & & \\
\hline$\cdot, \cdot 0$ & الجدولية & المحسوبة & & & & \\
\hline \multirow[t]{2}{*}{ دال } & \multirow[t]{2}{*}{1,99} & \multirow[t]{2}{*}{$1 \cdot, \leqslant 9$} & $10, Y V$ & $|r \varepsilon, v|$ & $1 \ldots$ & علمي \\
\hline & & & $r_{1}, \leqslant V$ & $1 \cdot v, \cdot 1$ & $1 \ldots$ & إنساني \\
\hline
\end{tabular}

الهذف الخامس/ التعرف على طبيعة العلاقة بين الثعور بالنقص ومعنى الحياة لاى طلبة الجامعة: لغرض التحقق من هذا الهدف نم استخراج معامل ارتباط بيرسون بين الثعور بالنقص بعل ومعنى الحياة حيث بلغ (דه ب, ·) ، ولغرض معرفة دلالة طبيعة هذه العلاقة فقد نم استخراج

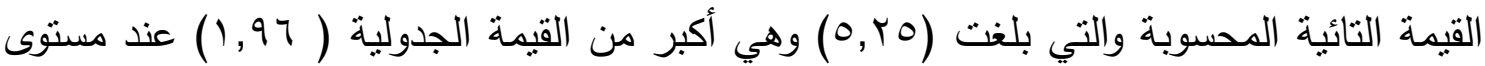

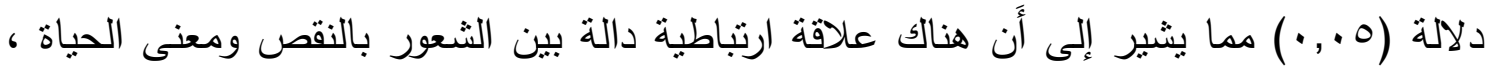
وكما موضح في الجدول (19 (1). 


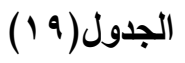

قيمة معامل الارتباط والقيمة التائية

\begin{tabular}{|c|c|c|c|c|}
\hline \multirow{2}{*}{ الدالة } & \multicolumn{2}{|c|}{ القيمة التائية لالالة معامل الارتباط } & \multirow{2}{*}{ قيمة معامل الارتباط بين الثعور } & \multirow[b]{2}{*}{ العدد } \\
\hline & الجدولية & المحسوبة & & \\
\hline 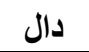 & 1,99 & $0, r_{0}$ & $\cdot, r 04$ & r... \\
\hline
\end{tabular}

ثانياً/ تفسير النتائج:

1- ـ إنَّ عينة البحث لديها شعوراً بالنقص أعلى من المتوسط الفرضي. و هذا ما اثشار اليه ادلر

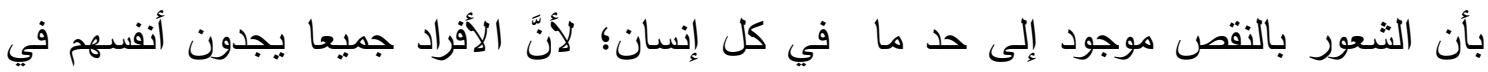

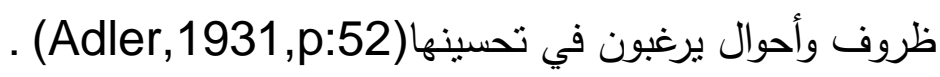

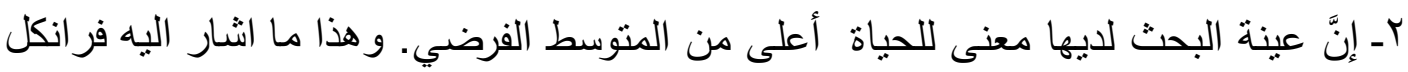

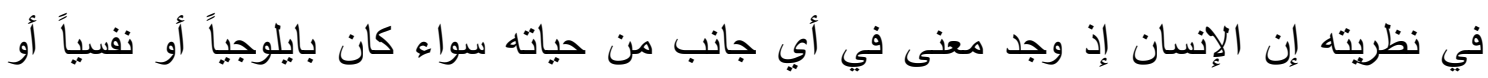

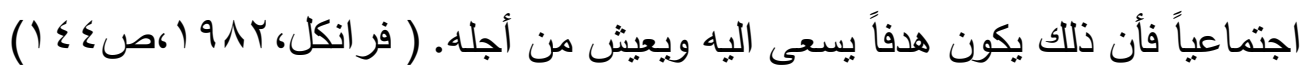
rـ توجد فروق في الثُعور بالنقص بين (الذكور. الاناث ) ولصالح الاناث، أبي أنَّ الاناث

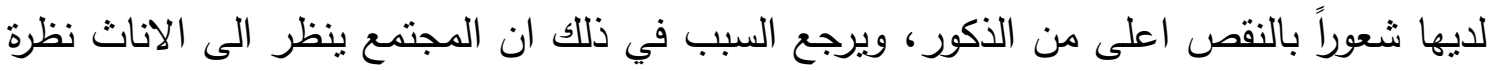
الضعف والتبعية والخنوع وعدم المساواة مع الذكور، مما ولد لايها شعوراً بالنقص.

(Adler,1931,p:65)

عـ لا توجد فروق في الثثعور بالنقص بين التخصص (علمي ـ انساني ). يعود ذلك الى ان طلبة الجامعة ضمن التخصصات العلمية والانسانية يقعون ضمن بيئة ثقافية واحدة، ولا يكون هنالك تمييز بينهما.

هـ توجد فروق في معنى الحياة بين ( الذكور ـ اناث ) ولصالح الذكور ، ويعود ذللك الى ان

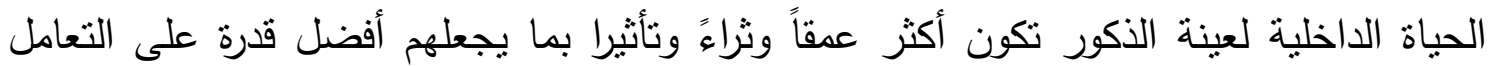
الجيد مع أقسى الظروف المحيطة به وبالتالي يكون لديهم معنى للحياة اعلى من الاناث.

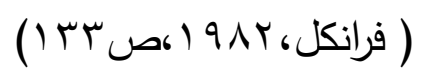

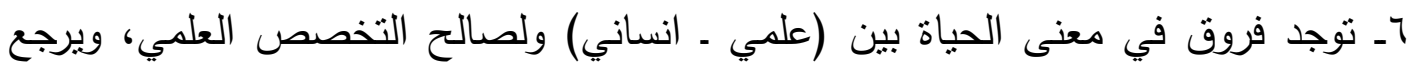
سبب ذلك لان الطلبة ذوب التخصص العلمي يكون لديهم مسنوى الطموح اعلى من التخصص

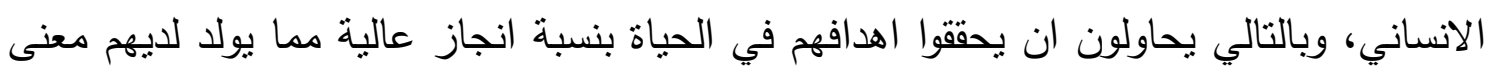

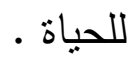

V- توجد علاقة ارتباطية بين الثعور بالنقص ومعنى الحياة. ويمكن تفسير ذلك هو ان

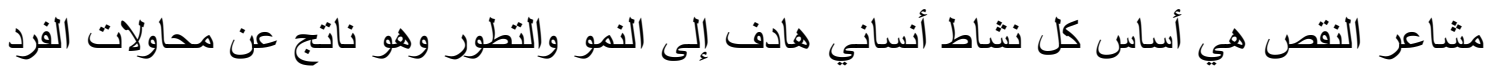
المختلفة بقصد تعويض هذا النقص سواء أكان هذا النقص حقيقياً أو منوهماً فالإنسان بحاجة إلى الفى 
السعي والكدح في سبيل هدف يستحق أن يعيش من أجله. فلا شئ يعين الإنسان على البقاء والاستمرار والثبات في أحلك الظروف منل معرفته أن هناك معنى في حياته.

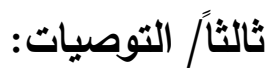

في ضوء النتائج التي توصل إليها الباحث ، يوصي بما يأني :

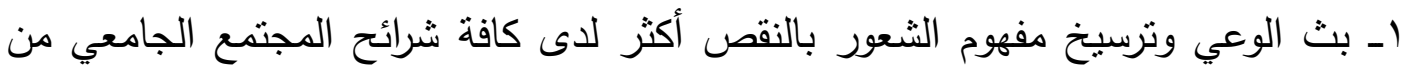
خلال الندوات والبرامج النطويرية. rـ العمل على تطوير مفهوم معنى الحياة أكثر لاى الطلبة.

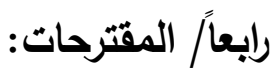

1 إجراء دراسة مماتلة على طلبة المراحل الإعدادية والمتوسطة . r- إجراء دراسة حول الثتعور بالنقص وعلاقتها بالإنجاز الاكاديمي لدى طلبة الجامعة.

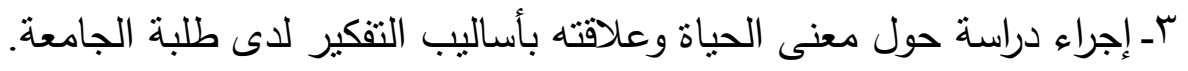

\section{المصادر:}

1. أدلر ، الفريد (؟ \9 (): الحياة النفسية ، ترجمة محمد بدران ،مطبعة لجنة التاليف والنشر، القاهرة

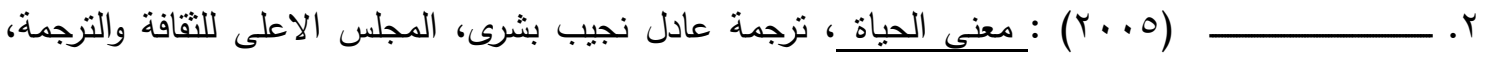

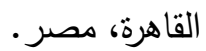

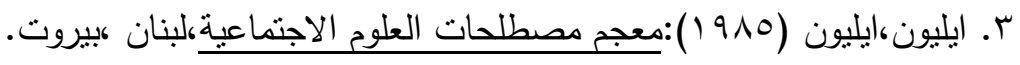
ع. باتر سون ، س ، هـ .( •99 ()) : نظريات الإرشاد والعلاج النفسي ـ ترجمة حامد عبد العزيز ألفقي، دار العلم

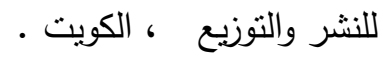

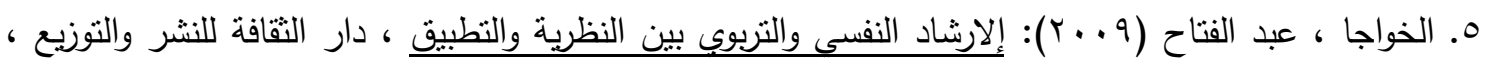
عمان.

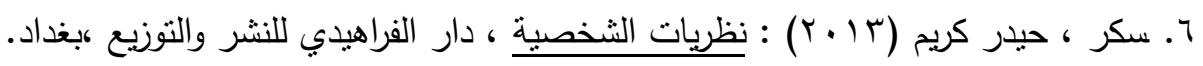

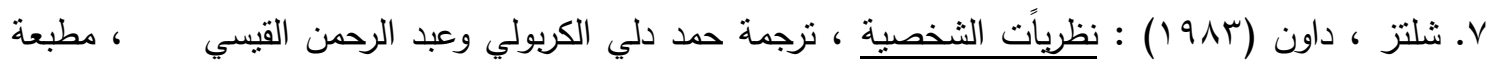

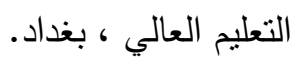

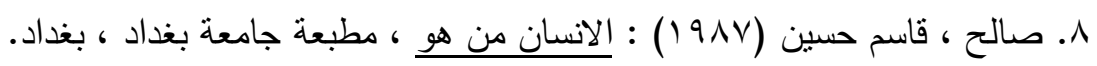

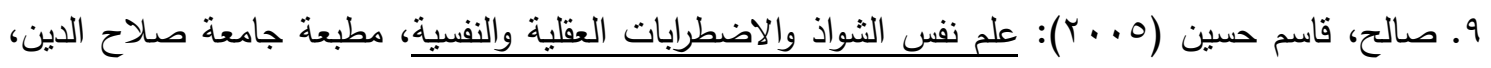

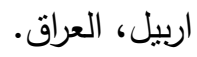

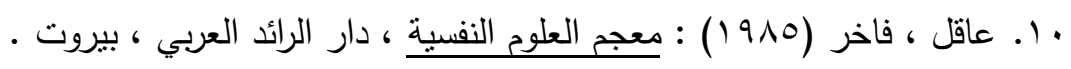

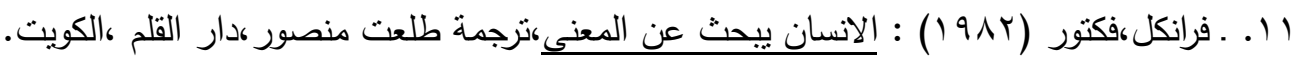

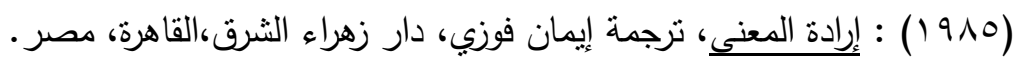
.14

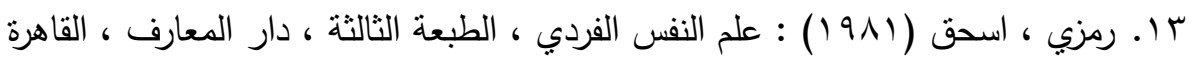

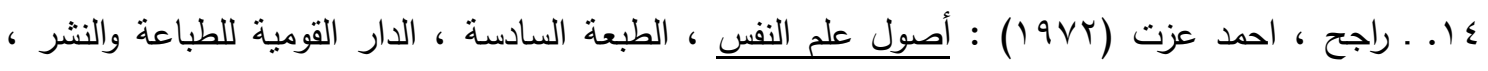


15. -Boeree,C(1997) : Personality Theories. , New York: John Wiley \&Sons, Inc. 16. -Chetan, J. (2009) . An empirical validation of Viktor Frank's Logotherapeutic Model. University of Missour-Kansas City

17. - Ryff, C, D. (1989). Happiness is everything, or is it? Explorations on the meaning of psychological well- being. Journal of personality \& Social Psychological .

18. -Adler, A(1931):What life should mean to you .Boston, Lettle\& Brown .

Kinner p.(2009): The meaning of Life in Relation with stress of life and neurotic dissrders, Journal of psychology. Vol.(11).

19. Nunnally,J.C.(1978): Psychometric theory, megraw.Hall,New York -

20. Thompson, J. (2008): Social Psychology, Mosby, New York -

21. - Thimos P., (2004): Meaning of alife their relation with social alienation, British Journal, Vol. (11).

22. - Guilford ,P .J.(1999) : General Psychology . London : Kcim- Hold Company

23. - Frankl ,V. E ( 1964 ). Man's Search for Meaning : An Introduction to

Logotherapy. London : Hodder and Stoughton .

- Child, I. L.and Whiting ,J. W (1995) :Determinats of level of Aspiration. Juornal of Abnormal and Social Psychology, V 44

\title{
inferiority Feeling and its relationship to the meaning of life in university students Dr. Amjad Kahdem Fares College of Imam Kadhim Islamic University of Science
}

\begin{abstract}
:
Inferiority is feeling haunt the individual in his life this feeling and correlates highly regarded low through the sense of the individual internally not psychological comfort, whether it was due to look at the individual third parties are good for himself or because he felt that the other Ninzeron him a negative view, therefore, individuals often suffer from this condition the lack of meaning in life and not knowing what they should do or what Aradoh, the individual who suffers from this condition manifests itself in a state of tension and boredom and internal void in himself always trying to escape from the daily life of the community free of meaning because of his activities that have no meaning, The current research aimed to identify the inferiority complex among university students as well. The meaning of life and the nature of the relationship between an inferiority complex and the meaning of life among college students, and require it to build tools to measure the feelings of inferiority and the meaning of life and the adoption of a unique theory of Adler, of the feeling of inferiority and the theory of Viktor Frankl of the meaning of life and the dish Almkiesan the research sample who are university students, and the results were the presence of a sense of inferiority and the meaning of life and there is a relationship between them, and there are differences between males and females in favor of females, but there are no differences between the scientific and humanitarian specialization for variable inferiority complex, as well as there are differences between males and females in favor of males, and specialization of scientific and humanitarian and in favor of scientific specialization to the variable meaning of life, and came out search a number of recommendations and proposals
\end{abstract}

